Prepared in cooperation with National Atmospheric and Oceanic Administration, National Marine Fisheries Service

Effects of the Proposed California WaterFix North Delta Diversion on Flow Reversals and Entrainment of Juvenile Chinook Salmon (Oncorhynchus tshawytscha) into Georgiana Slough and the Delta Cross Channel, Northern California

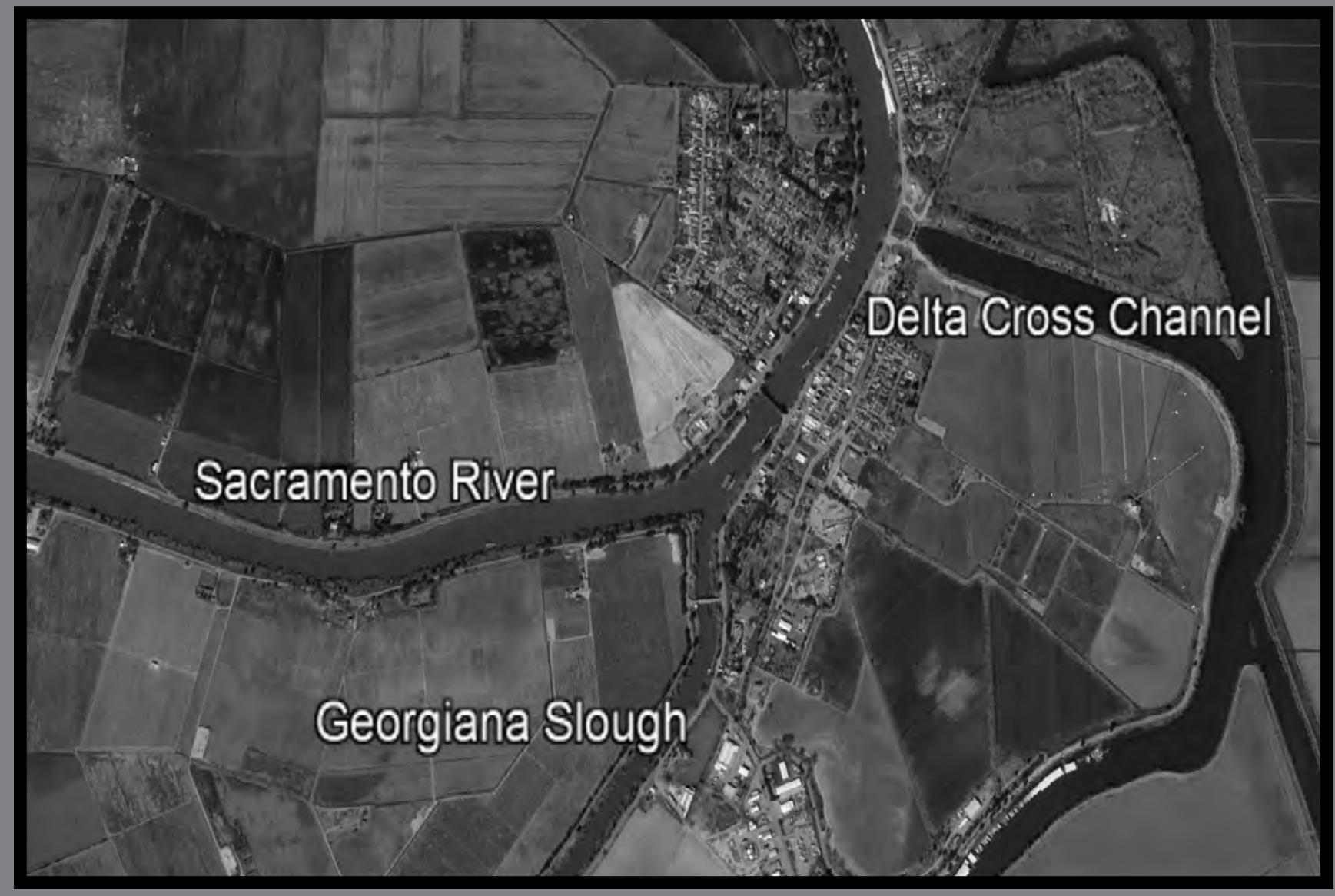

Open-File Report 2018-1028 
Cover: Image showing junction of the Sacramento River, Delta Cross Channel, and Georgiana Slough in the Sacramento-San Joaquin River Delta, northern California, February 21, 2014. Image source: Google Earth ${ }^{\mathrm{TM}}$. 


\section{Effects of the Proposed California WaterFix North Delta Diversion on Flow Reversals and Entrainment of Juvenile Chinook Salmon (Oncorhynchus tshawytscha) into Georgiana Slough and the Delta Cross Channel, Northern California}

By Russell W. Perry, Jason G. Romine, Adam C. Pope, and Scott D. Evans

Prepared in cooperation with National Atmospheric and Oceanic Administration, National Marine Fisheries Service

Open-File Report 2018-1028

U.S. Department of the Interior

U.S. Geological Survey 


\section{U.S. Department of the Interior \\ RYAN K. ZINKE, Secretary}

\section{U.S. Geological Survey \\ William H. Werkheiser, Deputy Director \\ exercising the authority of the Director}

U.S. Geological Survey, Reston, Virginia: 2018

For more information on the USGS-the Federal source for science about the Earth, its natural and living resources, natural hazards, and the environment-visit https://www.usgs.gov/ or call 1-888-ASK-USGS (1-888-275-8747).

For an overview of USGS information products, including maps, imagery, and publications, visit https:/store.usgs.gov.

Any use of trade, firm, or product names is for descriptive purposes only and does not imply endorsement by the U.S. Government.

Although this information product, for the most part, is in the public domain, it also may contain copyrighted materials as noted in the text. Permission to reproduce copyrighted items must be secured from the copyright owner.

Suggested citation:

Perry, R.W., Romine, J.G., Pope, A.C., and Evans, S.D., 2018, Effects of the proposed California WaterFix North Delta Diversion on flow reversals and entrainment of juvenile Chinook salmon (Oncorhynchus tshawytscha) into Georgiana Slough and the Delta Cross Channel, northern California: U.S. Geological Survey Open File Report 2018-1028, 46 p., https://doi.org/10.3133/ofr20181028.

ISSN 2331-1258 (online) 


\section{Contents}

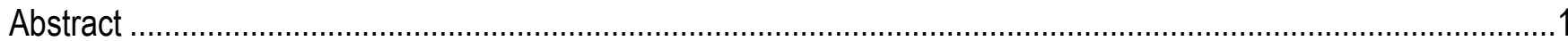

Evaluation of the Effects of the Proposed California WaterFix North Delta Diversion on Flow Reversals and Entrainment of Juvenile Chinook Salmon (Oncorhynchus tshawytscha) into Georgiana Slough and the

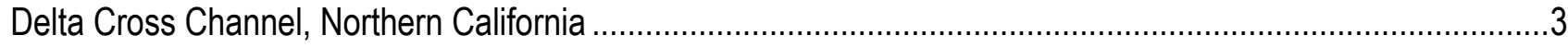

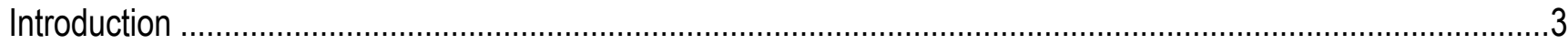

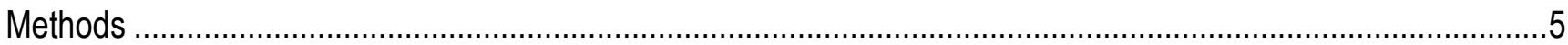

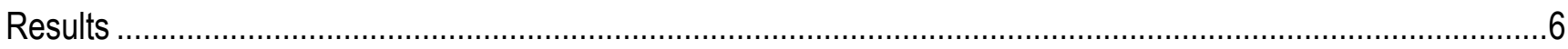

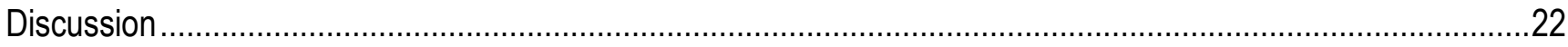

Corrections of Bias in Delta Simulation Model 2 Discharge Predictions at the Junction of the Sacramento River

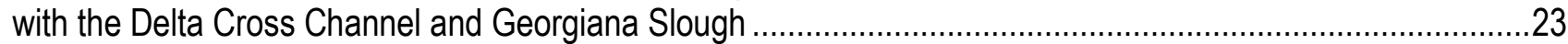

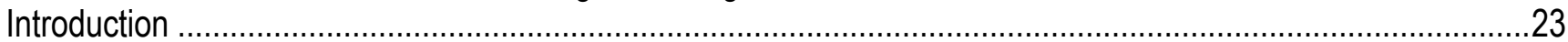

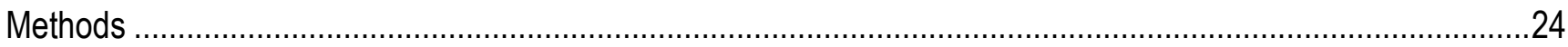

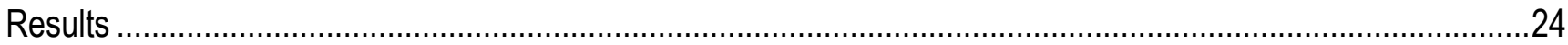

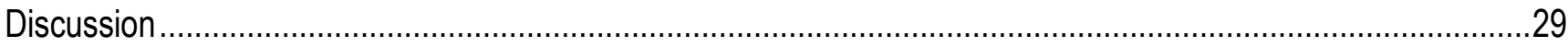

Simulation of Effects of the North Delta Diversion on Daily Entrainment Probability of Juvenile Chinook Salmon

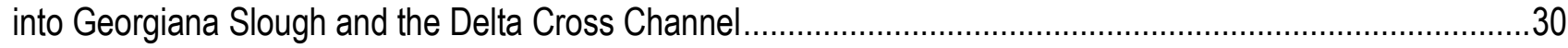

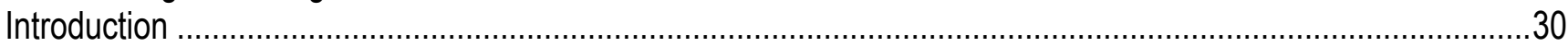

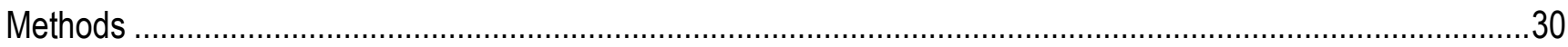

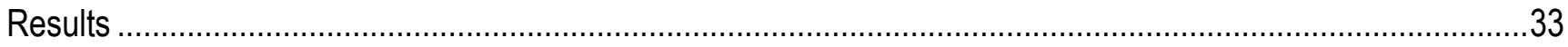

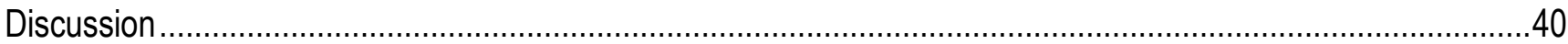

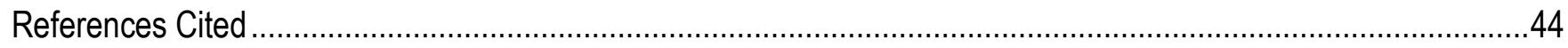

Appendix 1. Sensitivity Analysis_Differences between Scenarios for Day and Night Entrainment .....................45

\section{Figures}

Figure 1. Map showing Sacramento-San Joaquin River Delta with inset of detail of the junction of the Sacramento River with Georgiana Slough and the Delta Cross Channel, northern California

Figure 2. Graph showing effect of mean daily discharge on the probability of a flow reversal occurring on a given day with the Delta Cross Channel gate closed, at Freeport, on the Sacramento River just downstream of Georgiana Slough, northern California

Figure 3. Graphs showing effect of discharge on the duration of flow reversals at Freeport on the Sacramento River downstream of Georgiana Slough, northern California....

Figure 4. Graphs showing effect of North Delta Diversion (NDD) on bypass discharge, probability and increase in probability of flow reversal, and proportion of the day and increase in proportion of the day with reverse flow for constant low-level pumping as defined in the NDD bypass rules, at Freeport on the Sacramento River downstream of Georgiana Slough, northern California

Figure 5. Graphs showing effect of North Delta Diversion (NDD) on bypass discharge, probability and increase in probability of flow reversal, and proportion of the day and increase in proportion of the day with reverse flow for October-November as defined in the NDD bypass rules, at Freeport on the Sacramento River downstream of Georgiana Slough, northern California.....

Figure 6. Graphs showing effect of North Delta Diversion (NDD) on bypass discharge, probability and increase in probability of flow reversal, and proportion of the day and increase in proportion of the day with reverse flow for Level 1 post-pulse operations in December-April as defined in the NDD bypass rules, at Freeport on the Sacramento River downstream of Georgiana Slough, northern California. 
Figure 7. Graphs showing effect of North Delta Diversion (NDD) on bypass discharge, probability and increase in probability of flow reversal, and proportion of the day and increase in proportion of the day with reverse flow for Level 2 post-pulse operations in December-April as defined in the NDD bypass rules, at Freeport on the Sacramento River downstream of Georgiana Slough, northern California.

Figure 8. Graphs showing effect of North Delta Diversion (NDD) on bypass discharge, probability and increase in probability of flow reversal, and proportion of the day and increase in proportion of the day with reverse flow for Level 3 post-pulse operations in December-April as defined in the NDD bypass rules, at Freeport on the Sacramento River downstream of Georgiana Slough, northern California.

Figure 9. Graphs showing effect of North Delta Diversion (NDD) on bypass discharge, probability and increase in probability of flow reversal, and proportion of the day and increase in proportion of the day with reverse flow for Level 1 post-pulse operations in May as defined in the NDD bypass rules, at Freeport on the Sacramento River downstream of Georgiana Slough, northern California.

Figure 10. Graphs showing effect of North Delta Diversion (NDD) on bypass discharge, probability and increase in probability of flow reversal, and proportion of the day and increase in proportion of the day with reverse flow for Level 2 post-pulse operations in May as defined in the NDD bypass rules, at Freeport on the Sacramento River downstream of Georgiana Slough, northern California.

Figure 11. Graphs showing effect of North Delta Diversion (NDD) on bypass discharge, probability and increase in probability and increase in probability of flow reversal, and proportion of the day and increase in proportion of the day with reverse flow for Level 3 post-pulse operations in May as defined in the NDD bypass rules, at Freeport on the Sacramento River downstream of Georgiana Slough, northern California...

Figure 12. Graphs showing effect of North Delta Diversion (NDD) on bypass discharge, probability and increase in probability of flow reversal, and proportion of the day and increase in proportion of the day with reverse flow for Level 1 post-pulse operations in June as defined in the NDD bypass rules, at Freeport on the Sacramento River downstream of Georgiana Slough, northern California.

Figure 13. Graphs showing effect of North Delta Diversion (NDD) on bypass discharge, probability and increase in probability of flow reversal, and proportion of the day and increase in proportion of the day with reverse flow for Level 2 post-pulse operations in June as defined in the NDD bypass rules, at Freeport on the Sacramento River downstream of Georgiana Slough, northern California.

Figure 14. Graphs showing effect of North Delta Diversion (NDD) on bypass discharge, probability and increase in probability of flow reversal, and proportion of the day and increase in proportion of the day with reverse flow for Level 3 post-pulse operations in June as defined in the NDD bypass rules, at Freeport on the Sacramento River downstream of Georgiana Slough, northern California.

Figure 15. Graphs showing effect of North Delta Diversion (NDD) on bypass discharge, probability and increase in probability of flow reversal, and proportion of the day and increase in proportion of the day with reverse flow for July-September as defined in the NDD bypass rules, at Freeport on the Sacramento River downstream of Georgiana Slough, northern California

Figure 16. Graphs showing comparison of observed and regression-corrected discharge, during November 17-19, 2006; comparison of observed and predicted discharge; and residuals of predicted and observed discharge during 2007-11, at the Georgiana Slough near Sacramento River, northern California 26

Figure 17. Graphs showing comparison of observed, and regression-corrected discharge, during November 17-19, 2006; comparison of observed and predicted discharge; and residuals of the predicted and measured discharge during 2007-11, at the Sacramento River below Georgiana Slough, northern California....... 28 Figure 18. Graph showing daily probability of juvenile Chinook salmon entering the interior SacramentoSan Joaquin River Delta as a function of Sacramento River discharge at Freeport for the No Action Alternative and Proposed Action simulations done using Delta Simulation Model 2, northern California 
Figure 19. Graph showing run-timing scenarios used to estimate mean annual entrainment probabilities, with the early and late timings representing two scenarios for winter-run Chinook salmon in the Sacramento River, northern California, October-April

Figure 20. Graphs showing comparison of predicted mean annual juvenile Chinook salmon entrainment probability assuming uniform run timing for the Sacramento River, Georgiana Slough, and Delta Cross Channel between the Proposed Action, Sacramento-San Joaquin River Delta, northern California, water years 1922-2003.

Figure 21. Graphs showing comparison of predicted mean entrainment probability for the Sacramento River, Georgiana Slough, and Delta Cross Channel between the Proposed Action and No Action Alternative for uniform arrival and two different run timings for winter-run Chinook salmon, Sacramento-San Joaquin River Delta, northern California

Figure 22. Boxplots showing differences in predicted juvenile Chinook salmon entrainment probability between the Proposed Action and No Action Alternative by water year type and month assuming a uniform run timing, Sacramento-San Joaquin River Delta, northern California, October-June

Figure 23. Boxplots showing proportion of each month that the Delta Cross Channel was open for the No Action Alternative (NAA), Proposed Action (PA), and the difference between PA and NAA by water year type, Sacramento-San Joaquin River Delta, northern California.

Figure 24. Graphs showing comparison of bypass flows and predicted probability of juvenile Chinook salmon entrainment into Sacramento River, Georgiana Slough, and the Delta Cross Channel for the Proposed Action (PA) and No Action Alternative (NAA) when the DCC was open under PA but closed under NAA, SacramentoSan Joaquin River Delta, northern California, October 1-3, 1969

Figure 25. Boxplots showing predicted mean annual probability of juvenile Chinook salmon entrainment for the Sacramento River, Georgiana Slough, and Delta Cross Channel between the No Action Alternative and Proposed Action by water year type based on a uniform run-timing distribution, Sacramento-San Joaquin River Delta, northern California

Figure 26. Boxplots showing difference in predicted mean annual probability of juvenile Chinook salmon entrainment between No Action Alternative and Proposed Action for each route and run-timing scenario, Sacramento-San Joaquin River Delta, northern California

\section{Tables}

Table 1. Parameter estimates for the three logistic regression models used to estimate frequency and duration of flow reversals of the Sacramento River downstream of Georgiana Slough as a function of mean daily discharge at Freeport, northern California.....

Table 2. Parameter estimates for correction of flow at Georgiana Slough near Sacramento Rive, northern California.

Table 3. Parameter estimates for correcting Delta Simulation Model 2, version 8.0.6, predicted flow at Sacramento River below Georgiana Slough, northern California.

Table 4. Mean predicted annual entrainment probabilities under different run-timing scenarios for No Action Alternative and Proposed Action simulations done using Delta Simulation Model 2, Sacramento-San Joaquin River Delta, northern California. 


\section{Conversion Factors}

U.S. customary units to International System of Units

\begin{tabular}{|c|c|c|}
\hline Multiply & By & To obtain \\
\hline \multicolumn{3}{|c|}{ Area } \\
\hline MAF (million acre-feet) & $1,233.482$ & million cubic meters \\
\hline \multicolumn{3}{|c|}{ Flow rate } \\
\hline cubic foot per second $\left(\mathrm{ft}^{3} / \mathrm{s}\right)$ & 0.02832 & cubic meter per second $\left(\mathrm{m}^{3} / \mathrm{s}\right)$ \\
\hline national system or c & customary & To obtain \\
\hline \multicolumn{3}{|c|}{ Area } \\
\hline kilometer $(\mathrm{km})$ & 0.6214 & mile (mi) \\
\hline
\end{tabular}

\section{Abbreviations}

$\begin{array}{ll}\text { DCC } & \text { Delta Cross Channel } \\ \text { DSM2 } & \text { Delta Simulation Model 2 } \\ \text { NAA } & \text { No Action Alternative } \\ \text { NDD } & \text { North Delta Diversion } \\ \text { PA } & \text { Proposed Action } \\ \text { R2 } & \text { coefficient of determination } \\ \text { WYI } & \text { water year index }\end{array}$




\title{
Effects of the Proposed California WaterFix North Delta Diversion on Flow Reversals and Entrainment of Juvenile Chinook Salmon (Oncorhynchus tshawytscha) into Georgiana Slough and the Delta Cross Channel, Northern California
}

\author{
By Russell W. Perry, Jason G. Romine, Adam C. Pope, and Scott D. Evans
}

\begin{abstract}
The California Department of Water Resources and Bureau of Reclamation propose new water intake facilities on the Sacramento River in northern California that would convey some of the water for export to areas south of the Sacramento-San Joaquin River Delta (hereinafter referred to as the Delta) through tunnels rather than through the Delta. The collection of water intakes, tunnels, pumping facilities, associated structures, and proposed operations are collectively referred to as California WaterFix. The water intake facilities, hereinafter referred to as the North Delta Diversion (NDD), are proposed to be located on the Sacramento River downstream of the city of Sacramento and upstream of the first major river junction where Sutter Slough branches from the Sacramento River. The NDD can divert a maximum discharge of 9,000 cubic feet per second $\left(\mathrm{ft}^{3} / \mathrm{s}\right)$ from the Sacramento River, which reduces the amount of Sacramento River inflow into the Delta.

In this report, we conducted three analyses to investigate the effect of the NDD and its proposed operation on entrainment of juvenile Chinook salmon (Oncorhynchus tshawytscha) into Georgiana Slough and the Delta Cross Channel (DCC). Fish that enter the interior Delta (the network of channels to the south of the Sacramento River) through Georgiana Slough and the DCC survive at lower rates than fish that use other migration routes (Sacramento River, Sutter Slough, and Steamboat Slough). Therefore, fisheries managers were concerned about the extent to which operation of the NDD would increase the proportion of the population entering the interior Delta, which, all else being equal, would lower overall survival through the Delta by increasing the fraction of the population subject to lower survival rates. Operation of the NDD would reduce flow in the Sacramento River, which has the potential to increase the magnitude and duration of reverse flows of the Sacramento River downstream of Georgiana Slough.

In the first analysis, we evaluate the effect of the NDD bypass rules on flow reversals of the Sacramento River downstream of Georgiana Slough. The NDD bypass rules are a set of operational criteria designed to minimize upstream transport of fish into Georgiana Slough and the DCC, and were developed based on previous studies showing that the magnitude and duration of flow reversals increase the proportion of fish entering Georgiana Slough and the DCC. We estimated the frequency and duration of reverse-flow conditions of the Sacramento River downstream of Georgiana Slough under
\end{abstract}


each of the prescribed minimum bypass flows described in the NDD bypass rules. To accommodate adaptive levels of protection during different times of year when juvenile salmon are migrating through the Delta, the NDD bypass rules prescribe a series of minimum allowable bypass flows that vary depending on (1) month of the year, and (2) progressively decreasing levels of protection following a pulse flow event.

We determined that the NDD bypass rules increased the frequency and duration of reverse flows of the Sacramento River downstream of Georgiana Slough, with the magnitude of increase varying among scenarios. Constant low-level pumping, the most protective bypass rule that limits diversion to 10 percent of the maximum diversion and is implemented following a pulse-flow event, led to the smallest increase in frequency and duration of flow reversals. In contrast, we found that some scenarios led to sizeable increases in the fraction of the day with reverse flow. The conditions under which the proportion of the day with reverse flow can increase by greater than or equal to 10 percentage points between October and June, when juvenile salmon are present in the Delta, include October-November bypass rules and level-3 post-pulse operations during December-June. These conditions would be expected to increase the proportion of juvenile salmon entering the interior Delta through Georgiana Slough.

In the second analysis, we assessed bias in Delta Simulation Model 2 (DSM2) flow predictions at the junction of the Sacramento River, DCC, and Georgiana Slough. Because DSM2 was being used to simulate California WaterFix operations, understanding the extent of bias relative to USGS streamgages was important since fish routing models were based on flow data at streamgages. We determined that river flow predicted by DSM2 was biased for Georgiana Slough and the Sacramento River. Therefore, for subsequent analysis, we bias-corrected the DSM2 flow predictions using measured stream flows as predictor variables.

In the third analysis, we evaluated the effect of the NDD on the daily probability of fish entering Georgiana Slough and the DCC. We applied an existing model to predict entrainment from 15-minute flow simulations for an 82-year time series of flows simulated by DSM2 under the Proposed Action (PA), where the North Delta Diversion is implemented under California WaterFix, and the No Action Alternative (NAA), where the diversion is not implemented. To estimate the daily fraction of fish entering each river channel, entrainment probabilities were averaged over each day. To evaluate the two scenarios, we then compared mean annual entrainment probabilities by month, water year classification, and three different assumed run timings. Overall, the probability of remaining in the Sacramento River was lower under the PA scenario, but the magnitude of the difference was small ( $<1$ percentage point). When run timing was assumed to occur between December and April, this difference was even less because fish were less exposed to periods when we observed the largest difference in entrainment between scenarios (October and November). The difference in entrainment between scenarios primarily was influenced by the difference in operation of the DCC between PA and NAA. Under the PA scenario, the DCC was open more frequently in October, November, and June, thus exposing more fish to being entrained into the interior Delta by the DCC. It is important to note, however, that we may have observed even less difference in mean annual entrainment probabilities between PA and NAA because we restricted our analysis to flows less than $41,000 \mathrm{ft}^{3} / \mathrm{s}$. At flows greater than $41,000 \mathrm{ft}^{3} / \mathrm{s}$, we hypothesize that entrainment into the interior Delta is relatively constant, which would have caused little difference between scenarios at higher flows. 


\title{
Evaluation of the Effects of the Proposed California WaterFix North Delta Diversion on Flow Reversals and Entrainment of Juvenile Chinook Salmon (Oncorhynchus tshawytscha) into Georgiana Slough and the Delta Cross Channel, Northern California
}

\author{
Introduction
}

This analysis investigates the effects of the North Delta Diversion (NDD) bypass rules (California Department of Water Resources, 2013, table 3.4.1-2) on the frequency and duration of reverse flows of the Sacramento River downstream of Georgiana Slough (fig. 1), in the Sacramento-San Joaquin River Delta (hereinafter referred to as the Delta) of northern California. One goal of the NDD bypass rules is to provide bypass flows that prevent an increase in upstream transport of fish into Georgiana Slough and the Delta Cross Channel (DCC). Bypass flows are defined as flow remaining in the Sacramento River downstream of the North Delta Diversion. These rules were developed based on previous research and understanding of reverse-flow hydrodynamics at this river junction. Research has shown that the entrainment probability of juvenile Chinook salmon (Oncorhynchus tshawytscha) into Georgiana Slough and the DCC is highest during reverse-flow flood tides (Perry and others, 2015). Furthermore, the daily proportion of fish entrained into Georgiana Slough increases with the fraction of the day in a reverse flow condition at the Sacramento River downstream of Georgiana Slough (Perry, 2010). Therefore, diverting water from the Sacramento River could increase the frequency and duration of reverse-flow conditions, thereby reducing survival by increasing the proportion of fish entrained into the interior Delta where survival probabilities are lower than in the Sacramento River (Perry and others, 2010, 2013).

The NDD bypass rules also are designed to provide more protection during times of the year when juvenile salmon populations are actively migrating through the Delta (primarily December-June) and during pulse flow events when endangered winter-run Chinook salmon are likely to initiate downstream migration into the Delta (del Rosario and others, 2013). To accommodate adaptive levels of protection, the NDD bypass rules prescribe a series of minimum allowable bypass flows that vary depending on (1) month of the year, and (2) progressively decreasing levels of protection following a pulse flow event. For modeling purposes, pulse events are defined based on discharge of the Sacramento River at Wilkins Slough, and minimum bypass levels are based on varying fractions of discharge of the Sacramento River arriving at the NDD (see California Department of Water Resources, 2013, table 3.4.1-2, for details). For operational purposes, pulse events are based on monitoring for the presence of winter-run-sized fish entering the reach.

Our goal was to estimate the frequency and duration of reverse-flow conditions of the Sacramento River downstream of Georgiana Slough under each of the prescribed minimum bypass flows described in the NDD bypass rules (California Department of Water Resources, 2013, table 3.4.12). First, we used historical flow data of the Sacramento River below Georgiana Slough (WGB; U.S. Geological Survey [USGS] streamgage 11447905) to estimate the effect of discharge of the Sacramento River at Freeport (FPT; USGS streamgage 11447650) on (1) the daily probability of a flow reversal, and (2) the daily proportion of each day with reverse flow. We then used these relationships to calculate the change in the probability of a flow reversal and the proportion of the day with reverse flow under each of the prescribed bypass flows described in the NDD bypass rules. 
This analysis assumed that (1) the NDD bypass rules are applied based on mean daily discharge at Freeport, and (2) that water is diverted at a constant discharge over an entire day such that the bypass flow is constant over the day. Thus, we assumed that the bypass is operated as strictly defined by the NDD bypass rules. We did not attempt to simulate "real time management" such as varying diversion flow at hourly timescales in response to in situ tidal conditions to prevent reverse flows. Such real-time management criteria have yet to be defined, and we, therefore, expanded on this topic in the discussion.

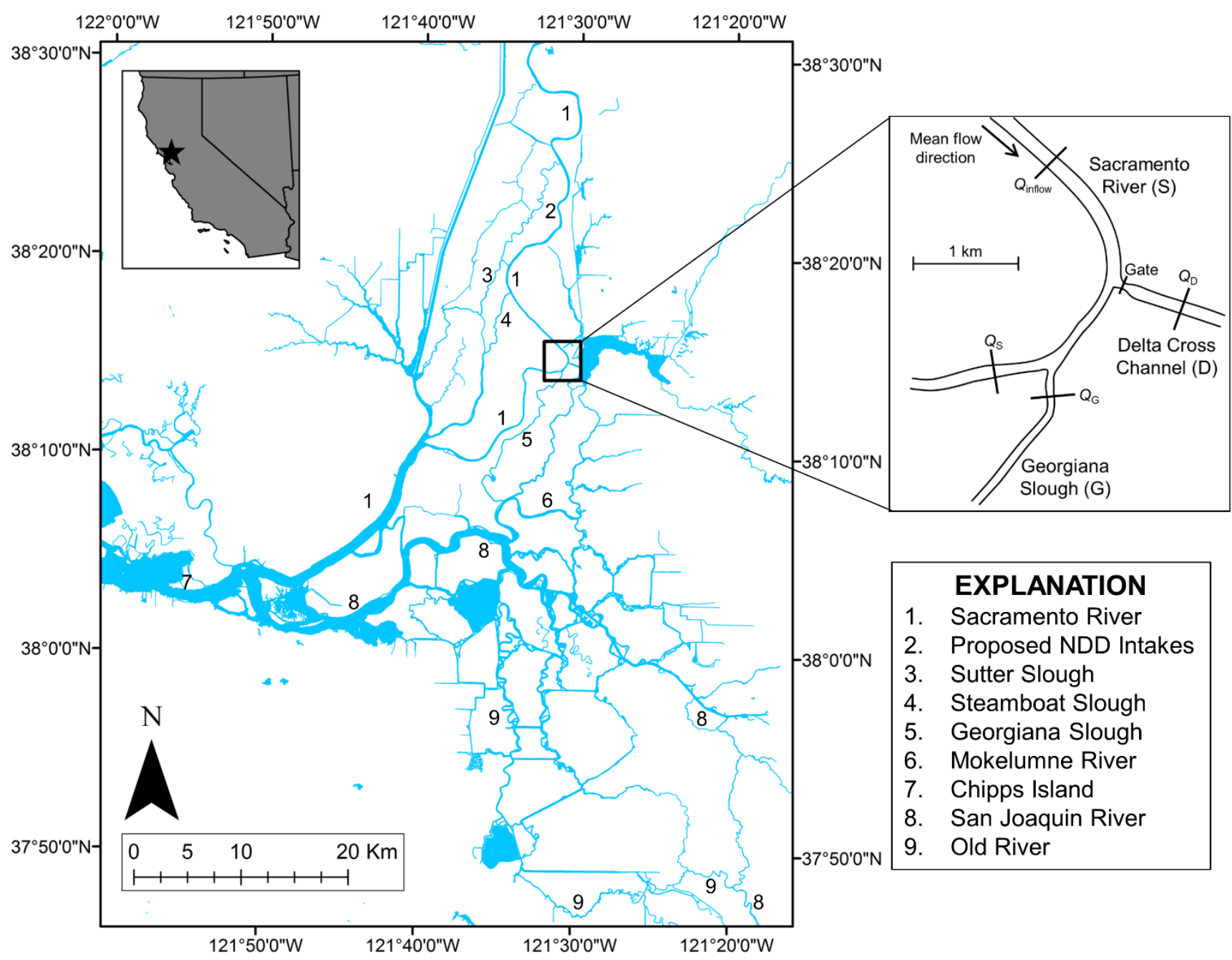

Figure 1. Map showing Sacramento-San Joaquin River Delta with inset of detail of the junction of the Sacramento River with Georgiana Slough and the Delta Cross Channel, northern California. Locations marked in inset map show streamgages. Qs, discharge of Sacramento River downstream of Georgiana Slough (U.S. Geological Survey streamgage 11447905); $Q_{D}$, discharge of the Delta Cross Channel (U.S. Geological Survey streamgage 11336600); QG, discharge of Georgiana Slough (U.S. Geological Survey streamgage 11447903); Qinflow, discharge of the Sacramento River upstream of the Delta Cross Channel (U.S. Geological Survey streamgage 11447890); NDD, North Delta Diversion; and km, kilometer. 


\section{Methods}

We used logistic regression to quantify the relationship between Sacramento River inflows to the Delta and reverse flows of the Sacramento River downstream of Georgiana Slough. Mean daily discharge at Freeport, 15-min discharge data at station WGB, and the daily position of the DCC gate for the period October 2007 to March 2015 were used in the analysis. The 15-min data at WGB was summarized to two daily statistics: (1) A binary indicator value that was set to 1 if reverse flow occurred at any point on a given day and set to 0 if all 15-min flows were positive, and (2) the number of 15-min flow observations for each day that were negative. The position of the DCC gate was coded as a binary indicator variable $(1=$ open, $0=$ closed $)$ for inclusion in the analysis. Dates without a complete record of 15-min flows at WGB or where the DCC gate was not open or closed for the entire day were excluded from the analysis.

To estimate the probability of a flow reversal occurring on a given day, we fit a logistic regression model to the binary indicator variable as a function of daily flow at Freeport:

$$
\mathrm{P}(\text { reverse })=\operatorname{logit}^{-1}\left(\alpha_{0}+\alpha_{1} Q_{\mathrm{FPT}}\right)
$$

where

logit-1 is the inverse logit function,

QFPT is mean daily discharge at Freeport,

$\alpha 0 \quad$ is the intercept, and

$\alpha 1 \quad$ is the slope.

We excluded the DCC gate position from this analysis because we noted that flow reversals always occurred for some part of the day when the DCC was open (that is, $\mathrm{P}$ [reverse $]=1$ for DCC open). Therefore, the analysis was restricted to days when the DCC was closed.

To estimate the proportion of the day with reverse flow as a function of Freeport flow, we fit a logistic regression model to the number of 15-min reverse flows on each day relative to the total number 15-min flow observations each day:

$$
\mathrm{P}_{\text {day }}(\text { reverse })=\operatorname{logit}^{-1}\left(\beta_{0}+\beta_{1} Q_{\mathrm{FPT}}\right)
$$

where

$\beta_{0} \quad$ is the intercept, and

$\beta_{1} \quad$ is the slope.

This analysis was conducted separately for periods with the DCC gate open and closed.

We used goodness-of-fit tests to evaluate whether the model adequately fit the data. Because the response variable was binary for the probability of a flow reversal on a given day, we used a HosmerLemeshow goodness-of-fit test (Hosmer and Lemeshow, 2000). For the binomial data used to estimate the proportion of each day with reverse flow, we used chi-square tests to evaluate goodness of fit (Faraway, 2006). In cases where these tests indicated lack of fit, we then used a quasibinomial regression to estimate the variance inflation factor, and then the variances, standard errors, and confidence intervals were inflated by this factor to account for overdispersion. 
Given the relationships estimating the effect of Freeport discharge on the frequency (P[reverse]) and duration ( $\mathrm{P}_{\text {day }}[$ reverse]) of flow reversals, we applied the bypass rules over a range of Freeport discharge from 5,000 to $35,000 \mathrm{ft}^{3} / \mathrm{s}$, which bracketed flows under which we observed a 100-percent probability of a flow reversal to a 0 -percent probability of a flow reversal. We compared the probability of flow reversal and the proportion of the day with flow reversals assuming no diversion and diversion under the NDD bypass rules with the DCC closed. We then calculated the difference in these statistics between no diversion and that prescribed under the NDD bypass rules to assess the magnitude of increase in the frequency and duration of reverse flows. Specifically, we did this comparison for the 12 scenarios described under the NDD bypass rules:

1. Constant low-level pumping,

2. October-November bypass rules,

3. Level 1,2, and 3 post-pulse operations for December-April,

4. Level 1,2, and 3 post-pulse operations for May,

5. Level 1,2, and 3 post-pulse operations for June, and

6. July-September bypass rules.

\section{Results}

Of the three logistic regressions used, only the analysis for $\mathrm{P}_{\text {day }}($ reverse) with the DCC closed had a significant goodness-of-fit test $\left(\chi_{1278}^{2}=2695, P<0.0001\right)$, indicating that the model did not capture all the variation in the observed data. Using quasibinomial regression, we estimated a variance inflation factor of 1.29 , which was used to inflate standard errors and confidence intervals.

We determined that the probability of a flow reversal decreased from 1.0 at about $12,500 \mathrm{ft}^{3} / \mathrm{s}$ to 0.0 at about $22,500 \mathrm{ft}^{3} / \mathrm{s}$ (fig. 2). We noted that the proportion of the day with negative flow was about 45 percent at a Freeport discharge of about $6,000 \mathrm{ft}^{3} / \mathrm{s}$ regardless of the DCC gate position (fig. 3). However, DCC gate position had a strong effect on the proportion of the day with reverse flows (table 1). As Freeport discharge increased over $6,000 \mathrm{ft}^{3} / \mathrm{s}$, the fraction of the day with reverse flows decreased much more sharply with the DCC closed relative to open (fig. 3). 


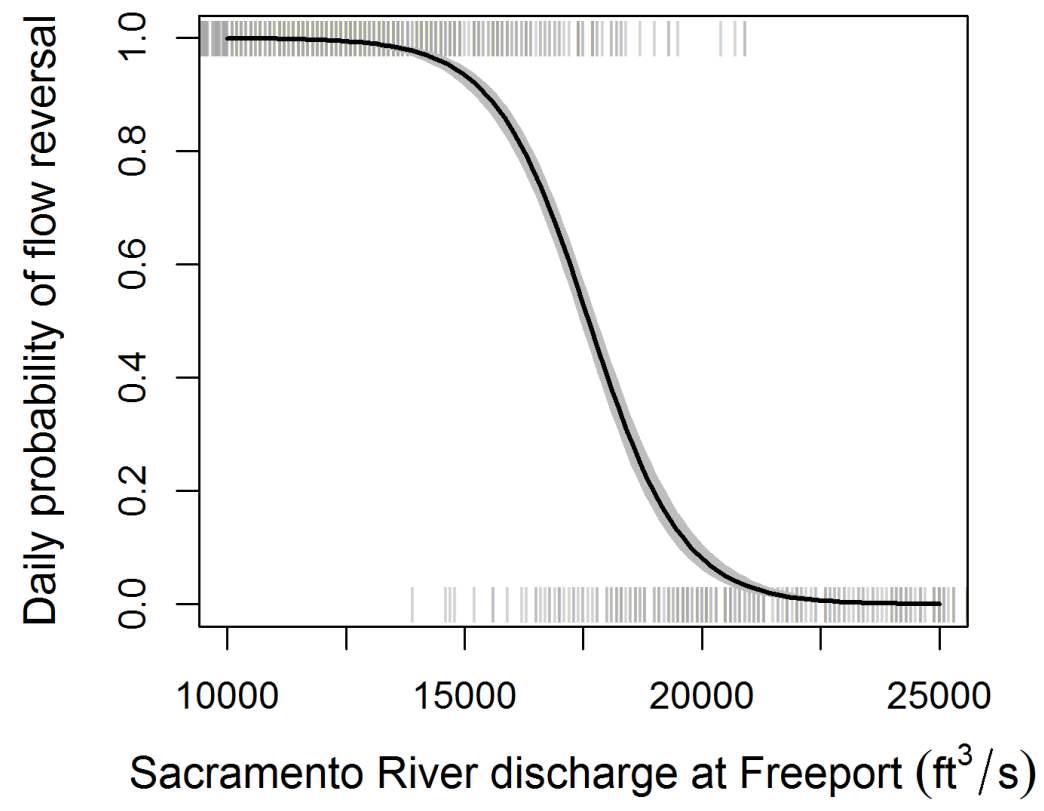

Figure 2. Graph showing effect of mean daily discharge on the probability of a flow reversal occurring on a given day with the Delta Cross Channel gate closed, at Freeport (USGS streamgage 11447650), on the Sacramento River just downstream of Georgiana Slough, northern California. Vertical bars show the days when flow reversals occurred (bars at 1.0) or did not occur (bars at 0.0 ), the black line shows the fitted logistic regression, and the gray regions on either side of this line show the 95-percent confidence interval about this line.

Table 1. Parameter estimates for the three logistic regression models used to estimate frequency and duration of flow reversals of the Sacramento River downstream of Georgiana Slough as a function of mean daily discharge at Freeport, northern California.

[DCC, Delta Cross Channel; SE, standard error; P, probability]

\begin{tabular}{lccc}
\hline \multicolumn{1}{c}{ Response variable } & DCC position & Intercept (SE) & Slope (SE) \\
\hline P(reverse) & Closed & $17.92(1.567)$ & $-1.017 \times 10^{-3}$ \\
& & & $\left(9.001 \times 10^{-5}\right)$ \\
P day (reverse) & Open & $0.13(0.021)$ & $-5.837 \times 10^{-5}$ \\
& & & $\left(1.600 \times 10^{-6}\right)$ \\
& Closed & $1.37(0.035)$ & $-2.409 \times 10^{-4}$ \\
& & & $\left(3.203 \times 10^{-6}\right)$ \\
\hline
\end{tabular}




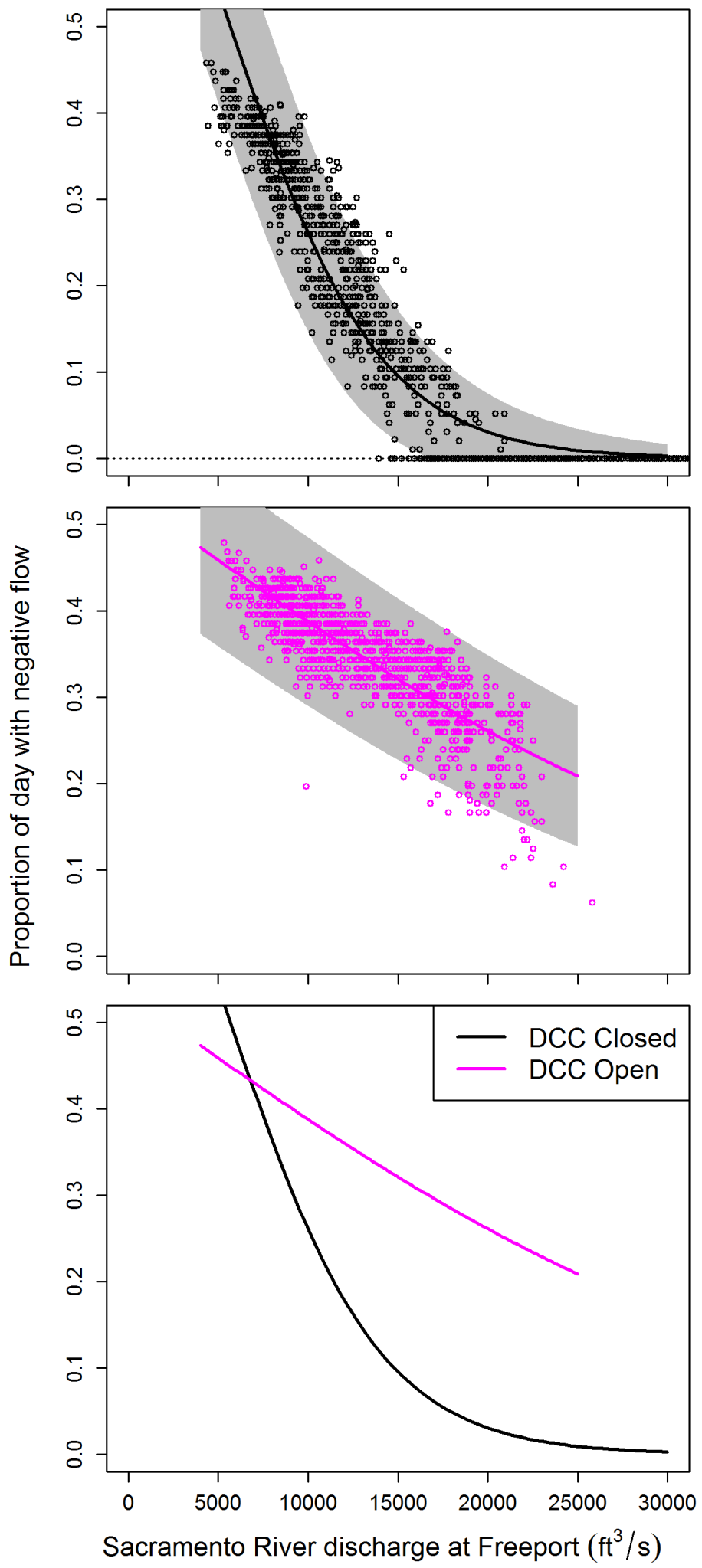

Figure 3. Graphs showing effect of discharge on the duration of flow reversals at Freeport (U.S. Geological Survey streamgage 11447650) on the Sacramento River downstream of Georgiana Slough, northern California. Shaded regions in top two graphs show 95-percent confidence intervals about the expected daily proportion. Bottom graph overlays the two curves to allow comparison. DCC, Delta Cross Channel. 
We determined that the NDD bypass rules, as implemented under the assumptions of our simulation, increased the frequency and duration of reverse flows of the Sacramento River downstream of Georgiana Slough, with the magnitude of increase varying among scenarios (figs. 4-15). Constant low-level pumping, the most protective bypass rule, led to the smallest increase in frequency and duration of flow reversals (fig. 4). For example, the probability of a flow reversal increased by a maximum of 22 percentage points at a Freeport discharge of $18,000 \mathrm{ft}^{3} / \mathrm{s}$, but the maximum increase in the proportion of the day with reverse flow increased by only 2.9 percentage points at a Freeport discharge of $10,000 \mathrm{ft}^{3} / \mathrm{s}$. In contrast, during December-April, when most populations of juvenile salmon are migrating through the Delta, level 3 post-pulse operations led to sizeable increases in the frequency and duration of flow reversals (fig. 8). Under these conditions, the probability of a flow reversal occurring increased from a 1 percent chance to a 99 percent chance at Freeport flows of 22,000 $\mathrm{ft}^{3} / \mathrm{s}$. More importantly, at this discharge, the proportion of each day with reverse flow increased by about 12 percentage points from 0.019 to 0.146 (fig. 8). These conditions would be expected to increase the proportion of juvenile salmon entering Georgiana Slough.

Juvenile salmon also are present in the Delta, albeit at lower abundances, during other periods with less restrictive bypass rules (for example, May, and October-November). Under OctoberNovember bypass rules, the proportion of the day with reverse flow increased by a maximum of 34 percentage points at a Freeport discharge of $16,000 \mathrm{ft}^{3} / \mathrm{s}$ (fig. 5). Under level 3 post-pulse operations in May, the proportion of the day with reverse flow is expected to increase by a maximum of 14.3 percentage points at a Freeport discharge of $21,400 \mathrm{ft}^{3} / \mathrm{s}$. 


\section{Constant Low-Level Pumping (Dec-Jun)}
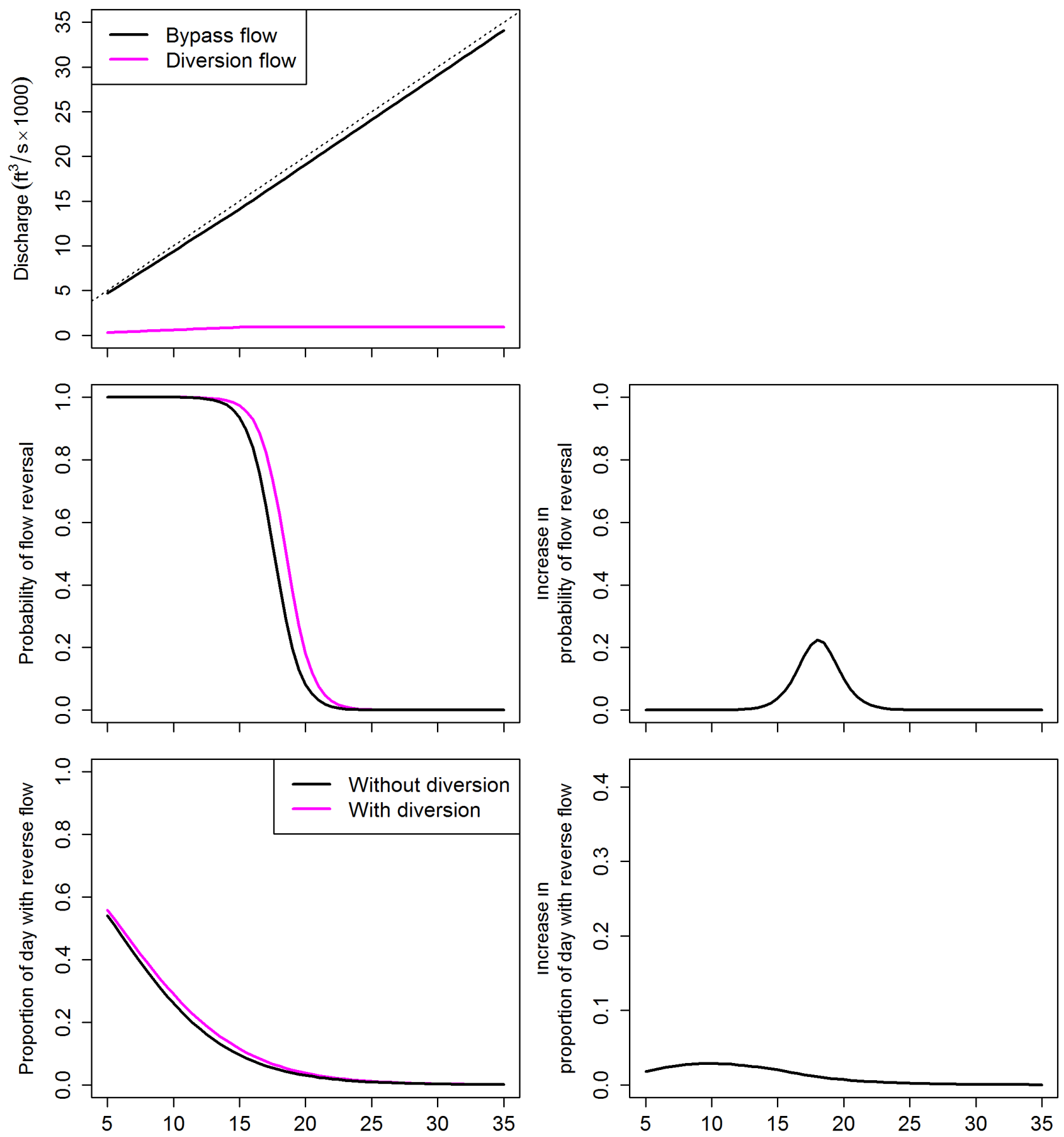

Sacramento River discharge at Freeport $\left(\mathrm{ft}^{3} / \mathrm{s} \times 1000\right)$

Figure 4. Graphs showing effect of North Delta Diversion (NDD) on bypass discharge (top graph), probability and increase in probability of flow reversal (middle graphs), and proportion of the day and increase in proportion of the day with reverse flow (bottom graphs) for constant low-level pumping as defined in the NDD bypass rules, at Freeport (U.S. Geological Survey streamgage 11447650) on the Sacramento River downstream of Georgiana Slough, northern California. In the top graph, the dotted line shows bypass discharge when diversion discharge is 0 . 


\section{Oct. - Nov. Bypass Rules}
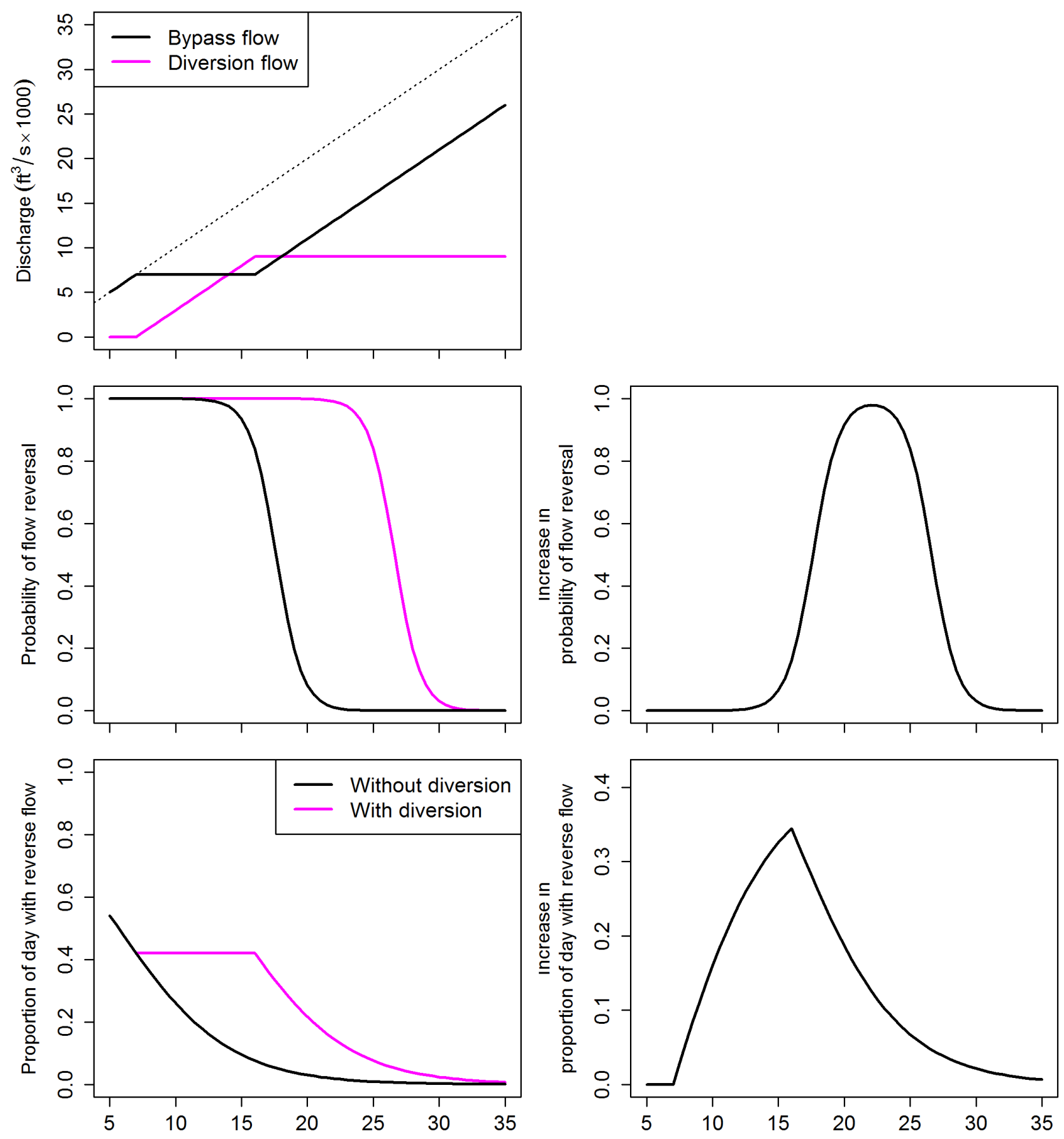

Sacramento River discharge at Freeport $\left(\mathrm{ft}^{3} / \mathrm{s} \times 1000\right)$

Figure 5. Graphs showing effect of North Delta Diversion (NDD) on bypass discharge (top graph), probability and increase in probability of flow reversal (middle graphs), and proportion of the day and increase in proportion of the day with reverse flow (bottom graphs) for October-November as defined in the NDD bypass rules, at Freeport (U.S. Geological Survey streamgage 11447650) on the Sacramento River downstream of Georgiana Slough, northern California. In the top graph, the dotted line shows bypass discharge when diversion discharge is 0 . 

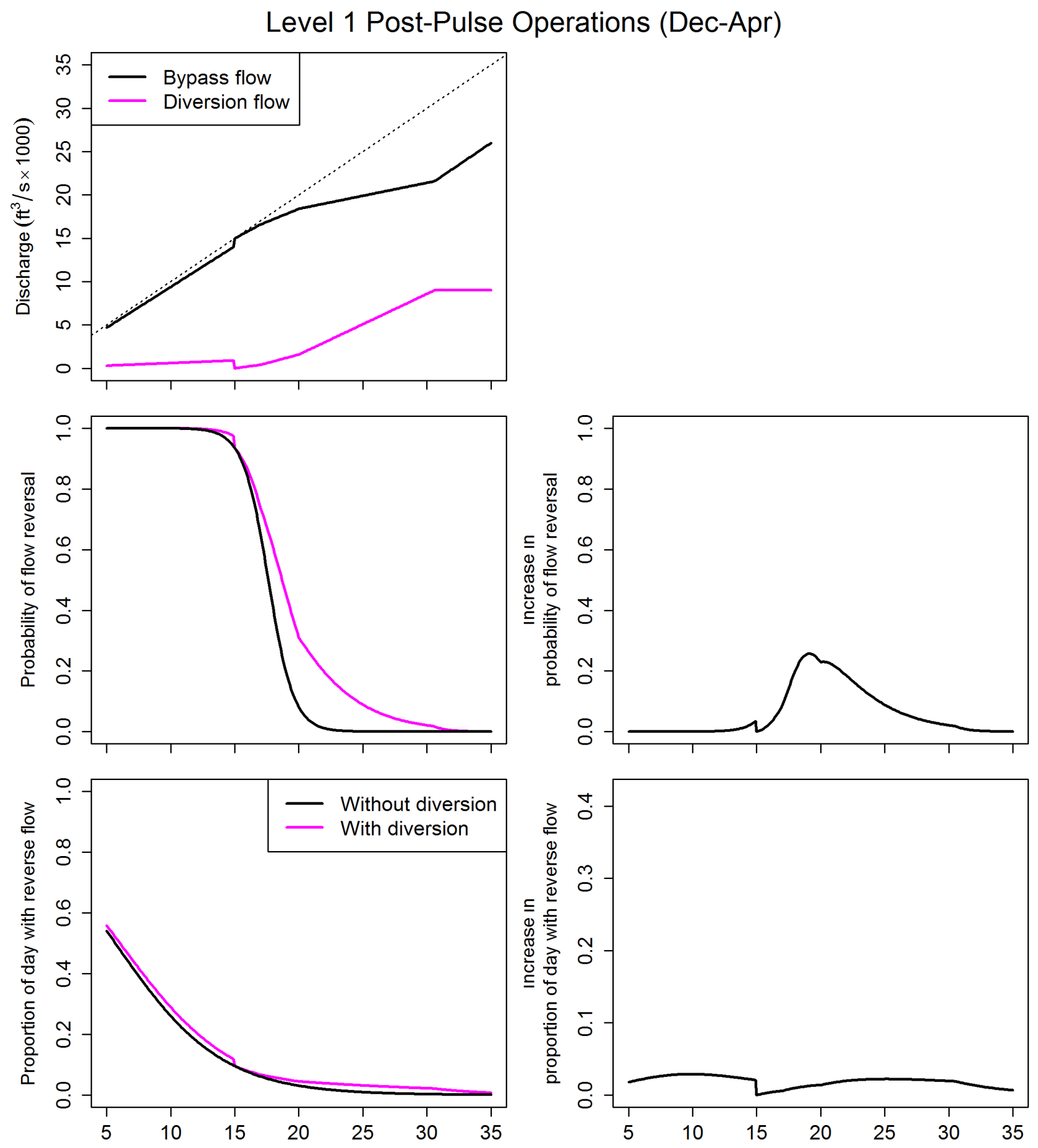

Sacramento River discharge at Freeport $\left(\mathrm{ft}^{3} / \mathrm{s} \times 1000\right)$

Figure 6. Graphs showing effect of North Delta Diversion (NDD) on bypass discharge (top graph), probability and increase in probability of flow reversal (middle graphs), and proportion of the day and increase in proportion of the day with reverse flow (bottom graphs) for Level 1 post-pulse operations in December-April as defined in the NDD bypass rules, at Freeport (U.S. Geological Survey streamgage 11447650) on the Sacramento River downstream of Georgiana Slough, northern California. In the top graph, the dotted line shows bypass discharge when diversion discharge is 0 . 
Level 2 Post-Pulse Operations (Dec-Apr)
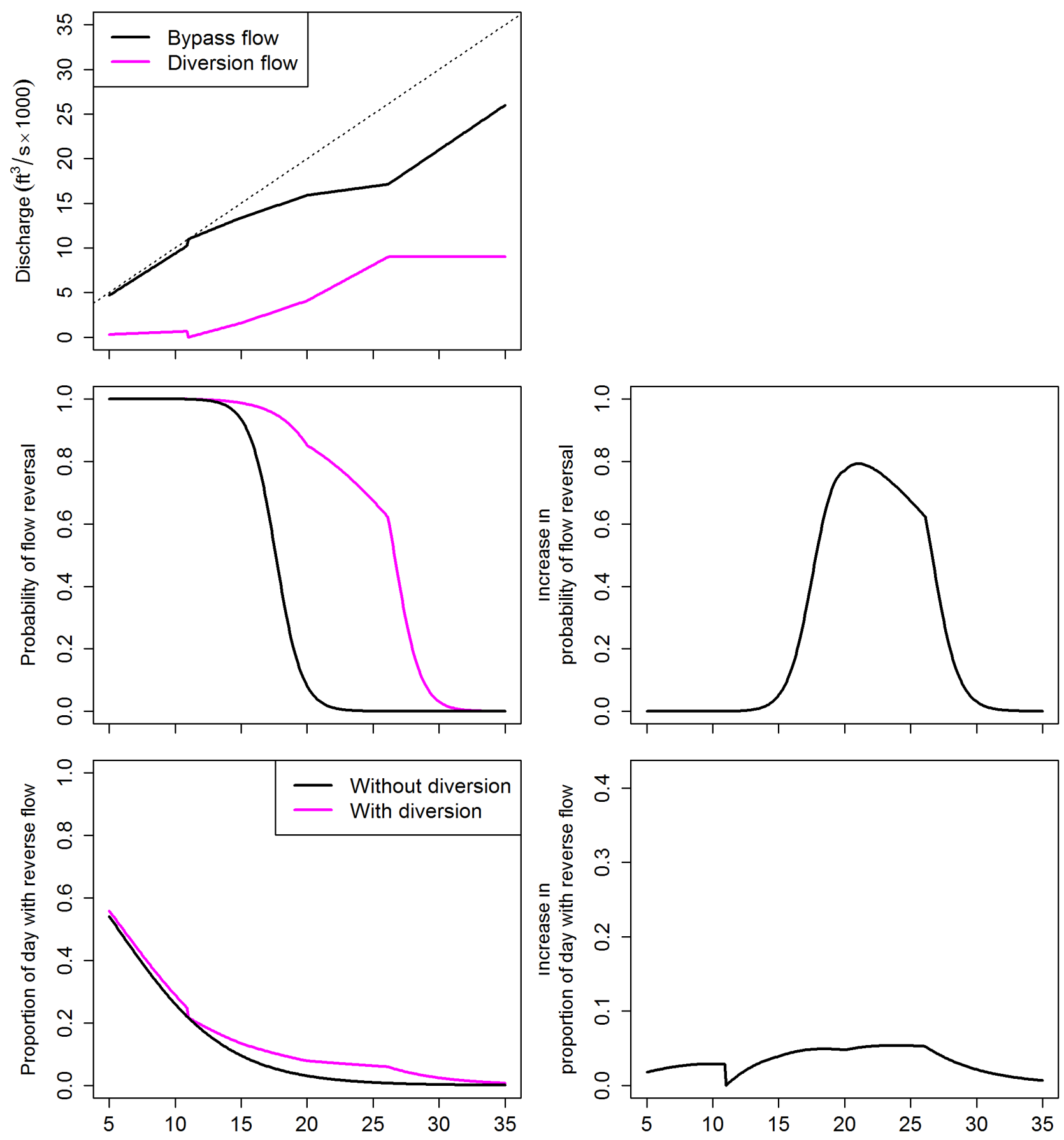

Sacramento River discharge at Freeport $\left(\mathrm{ft}^{3} / \mathrm{s} \times 1000\right)$

Figure 7. Graphs showing effect of North Delta Diversion (NDD) on bypass discharge (top graph), probability and increase in probability of flow reversal (middle graphs), and proportion of the day and increase in proportion of the day with reverse flow (bottom graphs) for Level 2 post-pulse operations in December-April as defined in the NDD bypass rules, at Freeport (U.S. Geological Survey streamgage 11447650) on the Sacramento River downstream of Georgiana Slough, northern California. In the top graph, the dotted line shows bypass discharge when diversion discharge is 0 . 

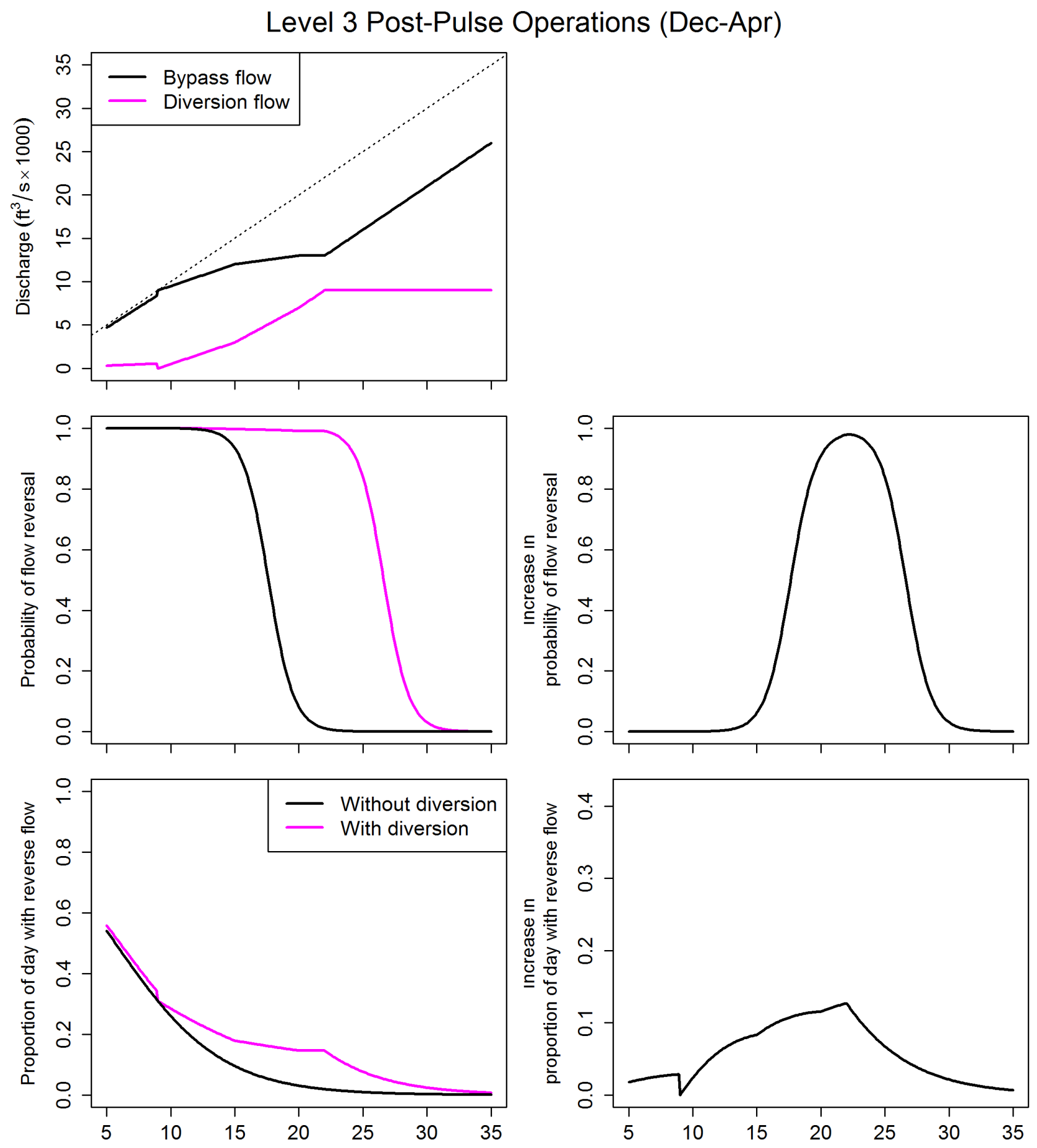

Sacramento River discharge at Freeport $\left(\mathrm{ft}^{3} / \mathrm{s} \times 1000\right)$

Figure 8. Graphs showing effect of North Delta Diversion (NDD) on bypass discharge (top graph), probability and increase in probability of flow reversal (middle graphs), and proportion of the day and increase in proportion of the day with reverse flow (bottom graphs) for Level 3 post-pulse operations in December-April as defined in the NDD bypass rules, at Freeport (U.S. Geological Survey streamgage 11447650) on the Sacramento River downstream of Georgiana Slough, northern California. In the top graph, the dotted line shows bypass discharge when diversion discharge is 0 . 
Level 1 Post-Pulse Operations (May)
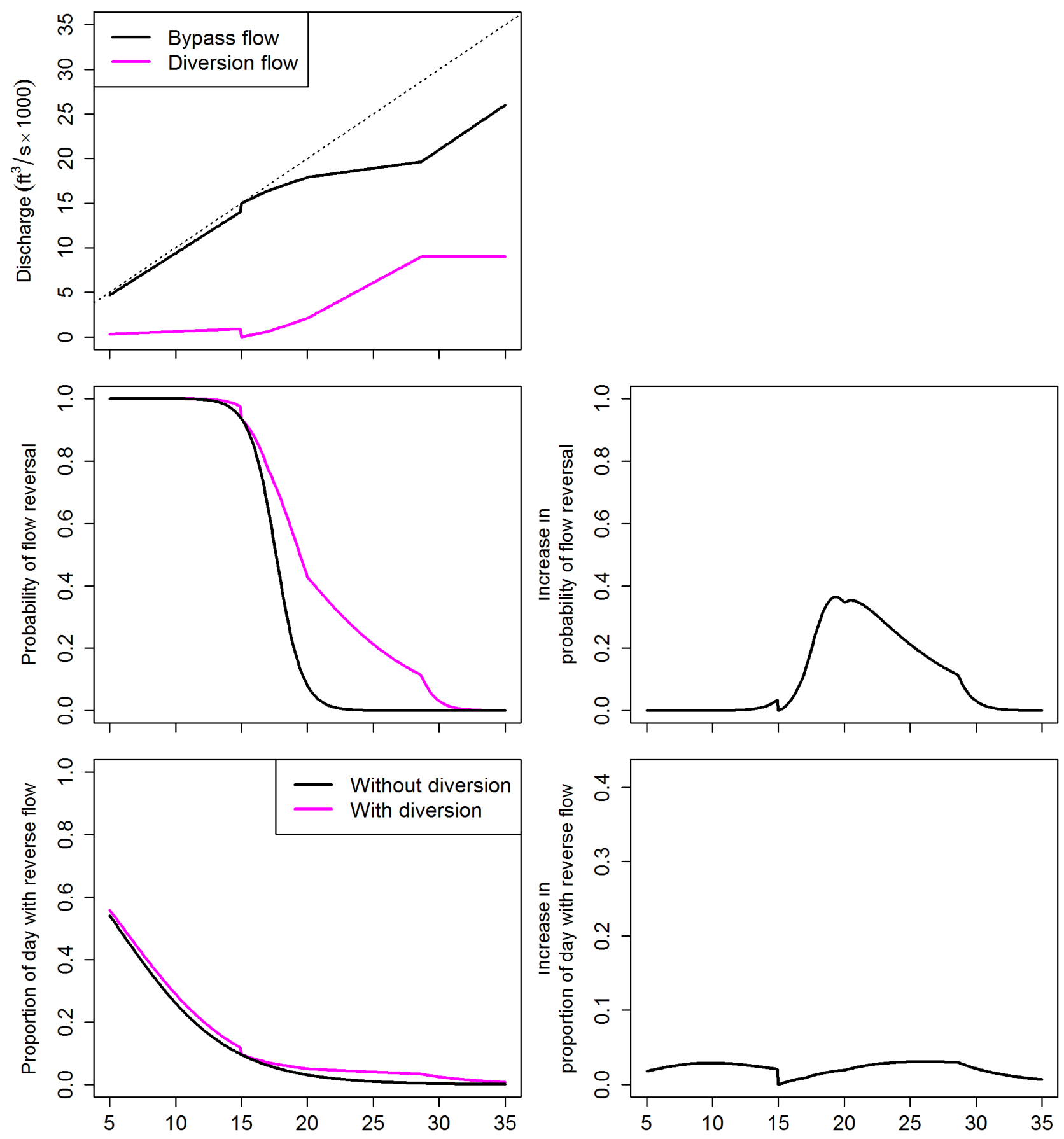

Sacramento River discharge at Freeport $\left(\mathrm{ft}^{3} / \mathrm{s} \times 1000\right)$

Figure 9. Graphs showing effect of North Delta Diversion (NDD) on bypass discharge (top graph), probability and increase in probability of flow reversal (middle graphs), and proportion of the day and increase in proportion of the day with reverse flow (bottom graphs) for Level 1 post-pulse operations in May as defined in the NDD bypass rules, at Freeport (U.S. Geological Survey streamgage 11447650) on the Sacramento River downstream of Georgiana Slough, northern California. In the top graph, the dotted line shows bypass discharge when diversion discharge is 0 . 


\section{Level 2 Post-Pulse Operations (May)}
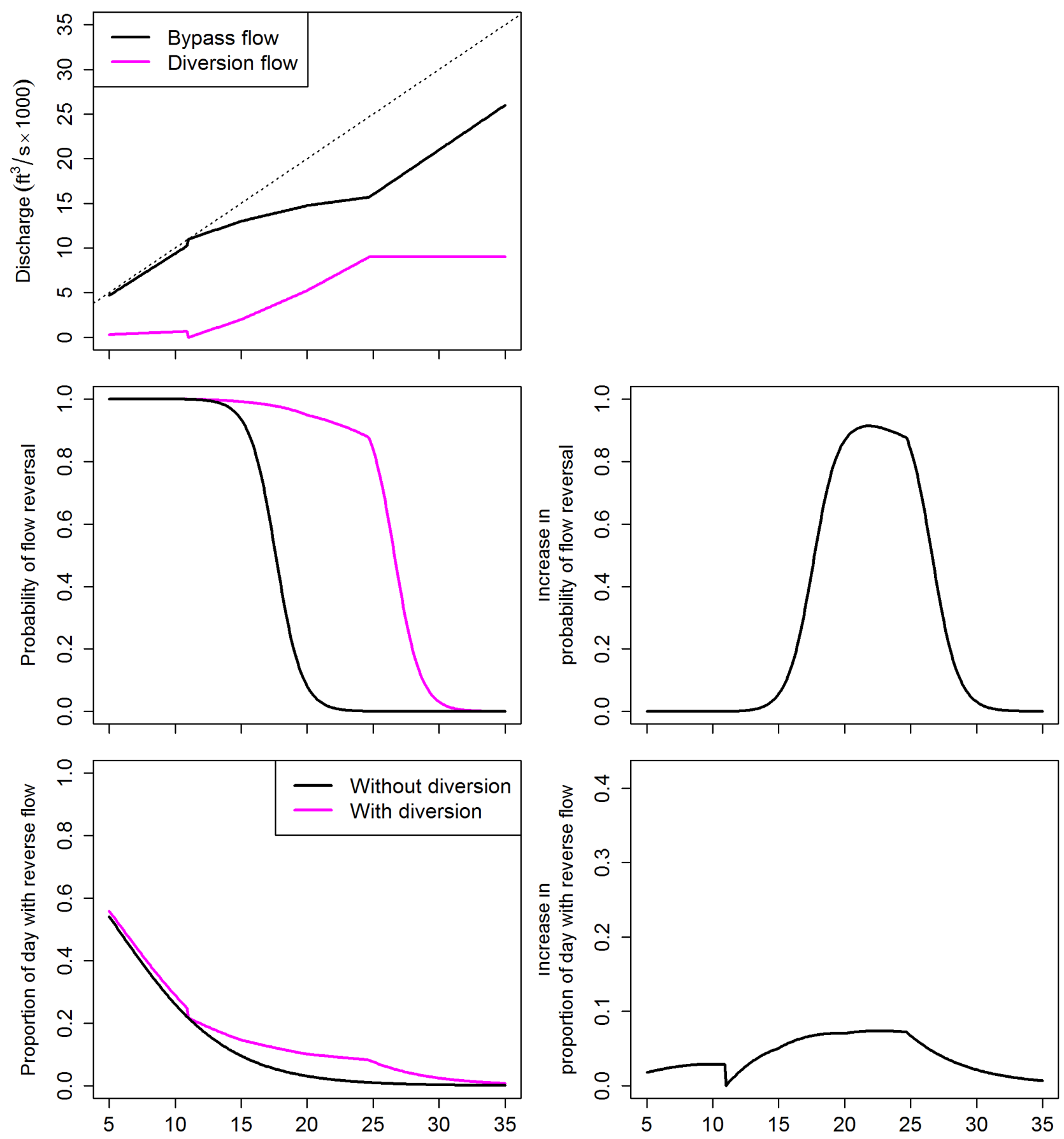

Sacramento River discharge at Freeport $\left(\mathrm{ft}^{3} / \mathrm{s} \times 1000\right)$

Figure 10. Graphs showing effect of North Delta Diversion (NDD) on bypass discharge (top graph), probability and increase in probability of flow reversal (middle graphs), and proportion of the day and increase in proportion of the day with reverse flow (bottom graphs) for Level 2 post-pulse operations in May as defined in the NDD bypass rules, at Freeport (U.S. Geological Survey streamgage 11447650) on the Sacramento River downstream of Georgiana Slough, northern California. In the top graph, the dotted line shows bypass discharge when diversion discharge is 0 . 
Level 3 Post-Pulse Operations (May)
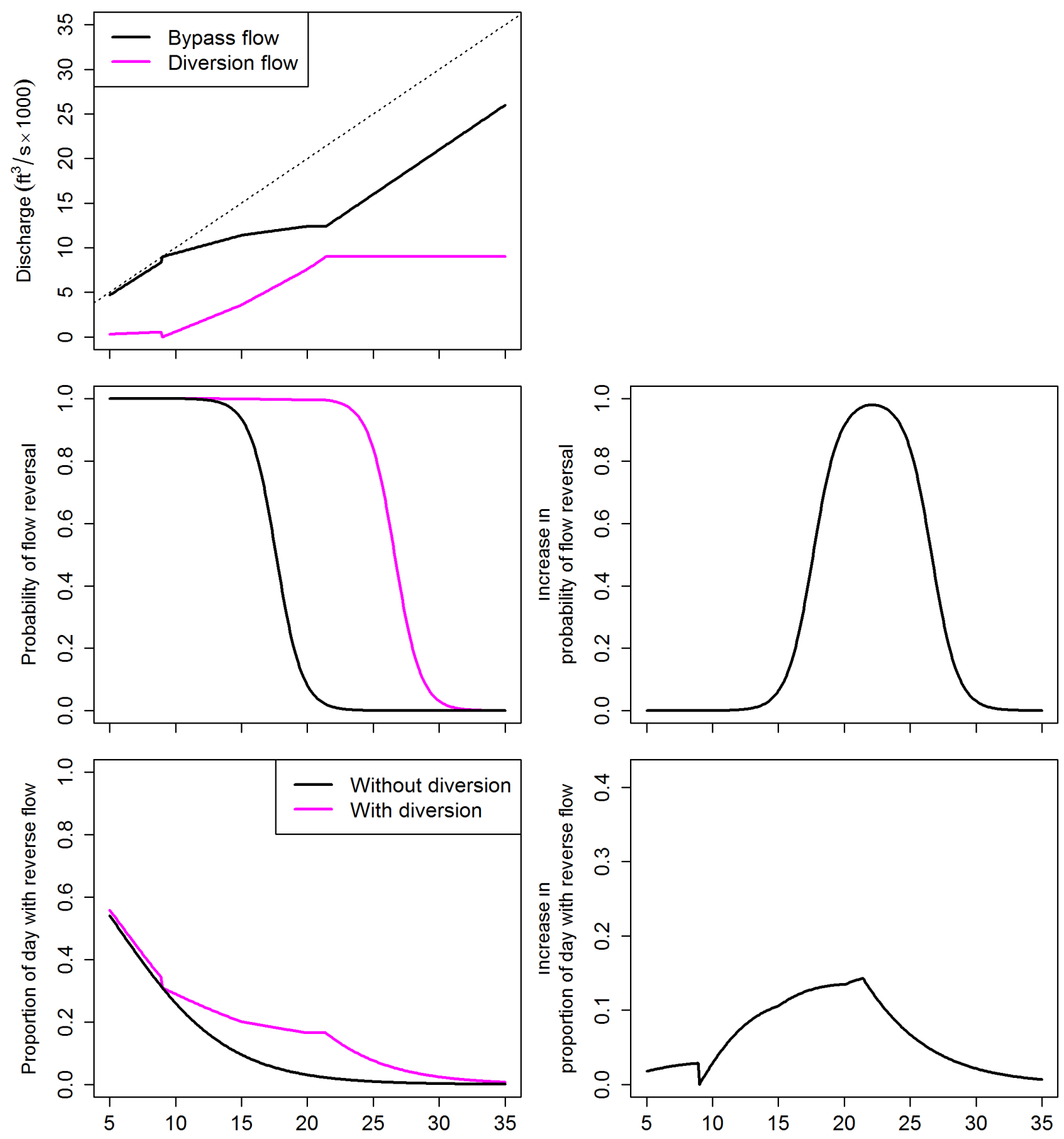

Sacramento River discharge at Freeport $\left(\mathrm{ft}^{3} / \mathrm{s} \times 1000\right)$

Figure 11. Graphs showing effect of North Delta Diversion (NDD) on bypass discharge (top graph), probability and increase in probability and increase in probability of flow reversal (middle graphs), and proportion of the day and increase in proportion of the day with reverse flow (bottom graphs) for Level 3 post-pulse operations in May as defined in the NDD bypass rules, at Freeport (U.S. Geological Survey streamgage 11447650) on the Sacramento River downstream of Georgiana Slough, northern California. In the top graph, the dotted line shows bypass discharge when diversion discharge is 0 . 
Level 1 Post-Pulse Operations (Jun)
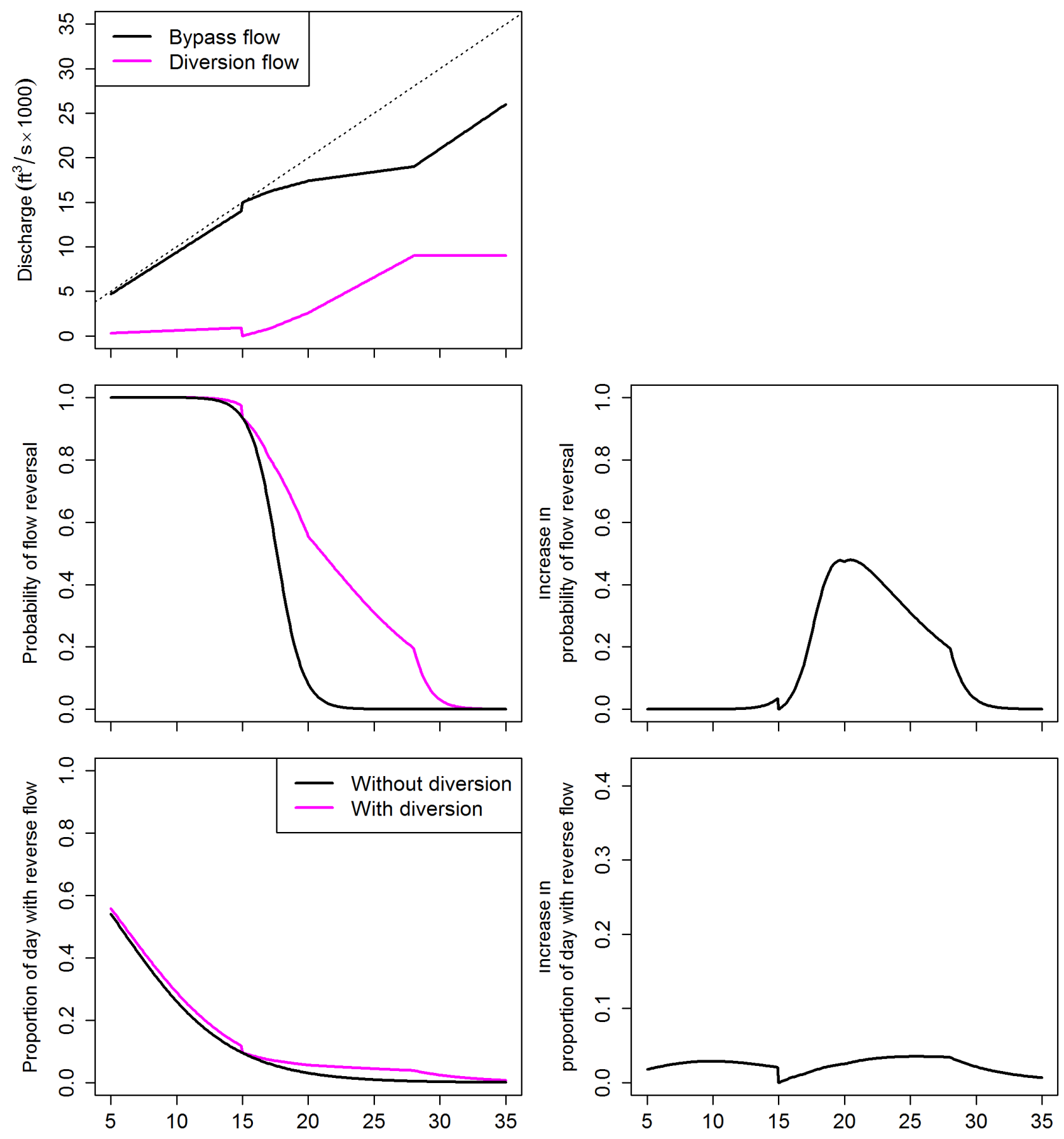

Sacramento River discharge at Freeport $\left(\mathrm{ft}^{3} / \mathrm{s} \times 1000\right)$

Figure 12. Graphs showing effect of North Delta Diversion (NDD) on bypass discharge (top graph), probability and increase in probability of flow reversal (middle graphs), and proportion of the day and increase in proportion of the day with reverse flow (bottom graphs) for Level 1 post-pulse operations in June as defined in the NDD bypass rules, at Freeport (U.S. Geological Survey streamgage 11447650) on the Sacramento River downstream of Georgiana Slough, northern California. In the top graph, the dotted line shows bypass discharge when diversion discharge is 0 . 
Level 2 Post-Pulse Operations (Jun)
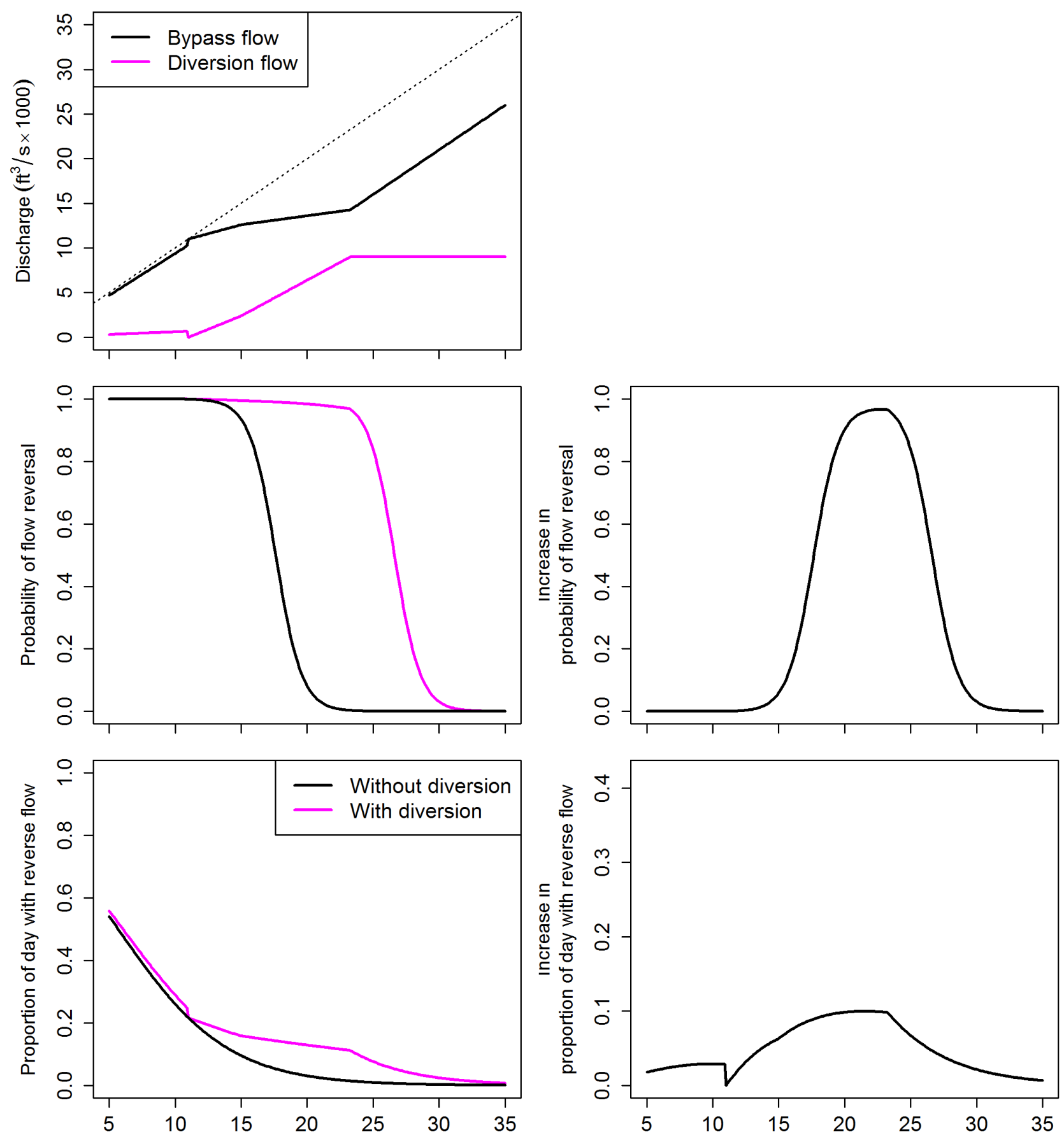

Sacramento River discharge at Freeport $\left(\mathrm{ft}^{3} / \mathrm{s} \times 1000\right)$

Figure 13. Graphs showing effect of North Delta Diversion (NDD) on bypass discharge (top graph), probability and increase in probability of flow reversal (middle graphs), and proportion of the day and increase in proportion of the day with reverse flow (bottom graphs) for Level 2 post-pulse operations in June as defined in the NDD bypass rules, at Freeport (U.S. Geological Survey streamgage 11447650) on the Sacramento River downstream of Georgiana Slough, northern California. In the top graph, the dotted line shows bypass discharge when diversion discharge is 0 . 
Level 3 Post-Pulse Operations (Jun)
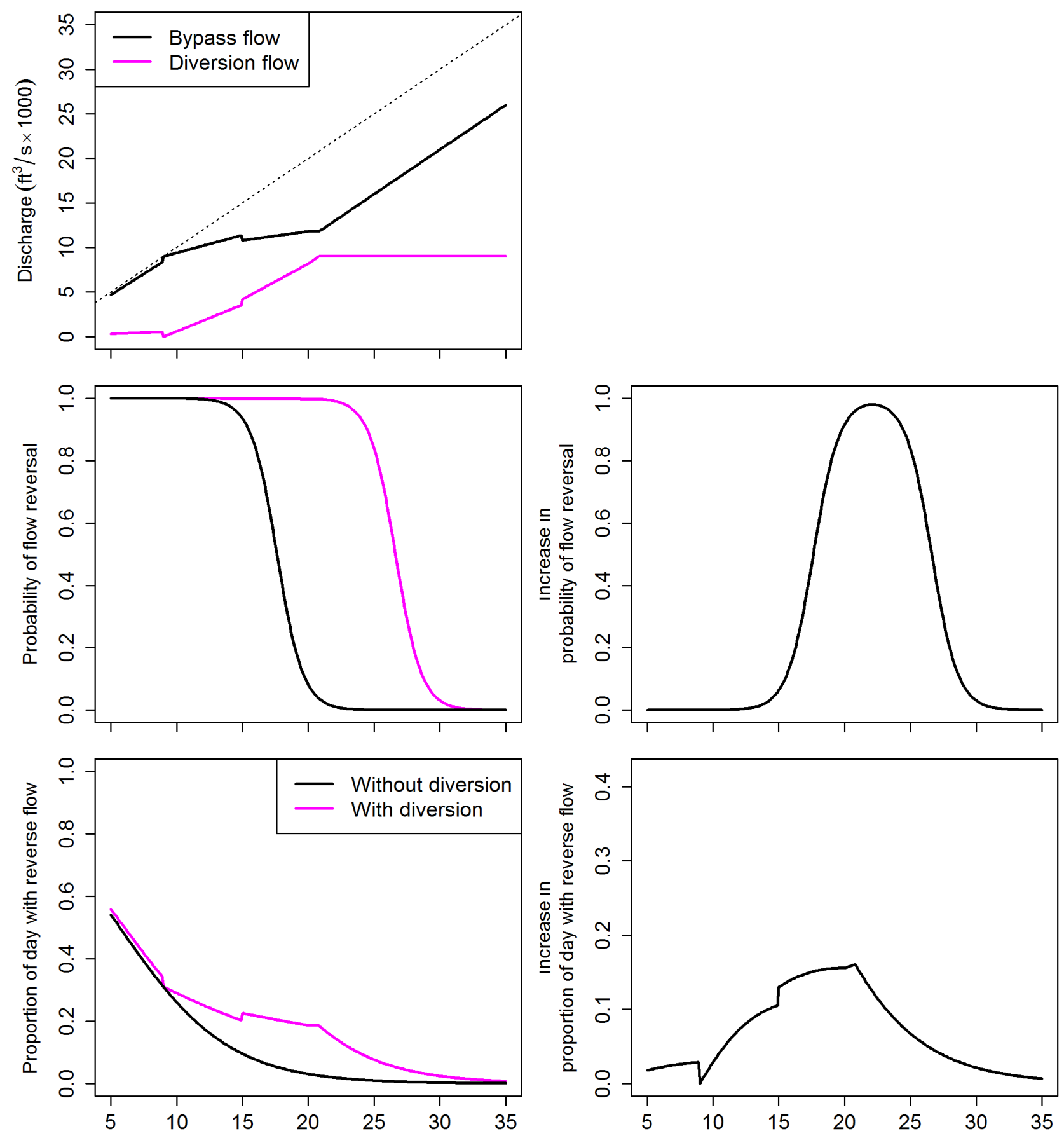

Sacramento River discharge at Freeport $\left(\mathrm{ft}^{3} / \mathrm{s} \times 1000\right)$

Figure 14. Graphs showing effect of North Delta Diversion (NDD) on bypass discharge (top graph), probability and increase in probability of flow reversal (middle graphs), and proportion of the day and increase in proportion of the day with reverse flow (bottom graphs) for Level 3 post-pulse operations in June as defined in the NDD bypass rules, at Freeport (U.S. Geological Survey streamgage 11447650) on the Sacramento River downstream of Georgiana Slough, northern California. In the top graph, the dotted line shows bypass discharge when diversion discharge is 0 . 
Jul. - Sep. Bypass Rules
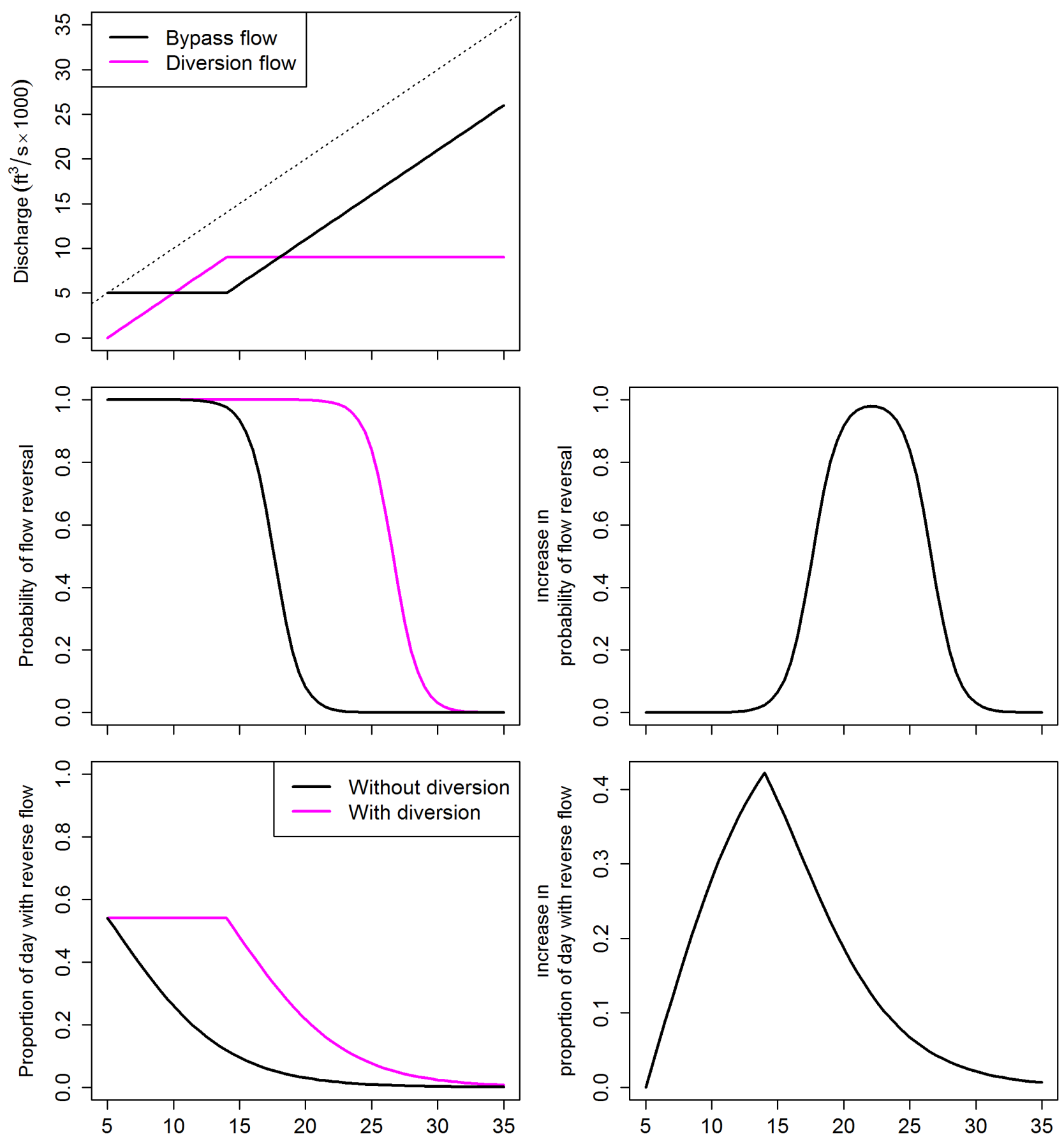

Sacramento River discharge at Freeport $\left(\mathrm{ft}^{3} / \mathrm{s} \times 1000\right)$

Figure 15. Graphs showing effect of North Delta Diversion (NDD) on bypass discharge (top graph), probability and increase in probability of flow reversal (middle graphs), and proportion of the day and increase in proportion of the day with reverse flow (bottom graphs) for July-September as defined in the NDD bypass rules, at Freeport (U.S. Geological Survey streamgage 11447650) on the Sacramento River downstream of Georgiana Slough, northern California. In the top graph, the dotted line shows bypass discharge when diversion discharge is 0 . 


\section{Discussion}

The NDD bypass rules are designed to allow for diversion of water from the Sacramento River while providing fish protection during peak migration periods into the Delta. Low-level pumping, which is initiated following flow pulses that have been shown to initiate migration of juvenile winter-run Chinook salmon (del Rosario and others, 2013), limits diversion to 10 percent of the maximum diversion capacity $\left(9,000 \mathrm{ft}^{3} / \mathrm{s}\right)$. Under this criterion, we noted little increase in the proportion of day with reverse flow (fig. 3); therefore, we expect little increase in entrainment of juvenile salmon into Georgiana Slough. In contrast, we noted that the duration of flow reversal could be increased considerably during periods when juvenile salmon are likely to be migrating past Georgiana Slough. The conditions under which the $\mathrm{P}_{\text {day }}$ (reverse) can increase by greater than or equal to $(\geq) 10$ percent between October and June include October-November bypass rules and level 3 post-pulse operations from December through June (see bottom right graphs in figs. 5, 8, 11, and 14).

We did our analysis under the assumption that the North Delta Diversion was operated at a constant rate for an entire day and followed the NDD bypass rules based on daily mean flows of the Sacramento River at Freeport. It generally is understood that the diversion would be operated "in real time" to prevent reverse flows at Georgiana Slough. However, a clear definition of control rules governing how the diversion would be operated to control flow reversals is required to evaluate the effect of "real time" operations on flow reversal. To our knowledge, such control rules have yet to be developed and evaluated using tools such as Delta Simulation Model 2 (DSM2). Therefore, our analysis evaluates the effect of the NDD bypass rules on flow reversals based on the how the rules were explicitly written according to readily available information on a daily basis (that is, Sacramento River flows at Freeport).

Although it is unclear how real-time operations would be implemented, the diversion could be operated on an hourly basis, in concert with the tides, to increase diversion during ebb tides but to restrict diversion during flood tides. Such operations likely would require detailed real-time predictions of tides and tidally varying river flow in order to account for variation in tidal cycles that affect the frequency, magnitude, and duration of reverse flows at a given Freeport discharge. The relationship between Sacramento River inflows with the probability of flow reversal and proportion of the day with reverse flow is driven by tidal cycles that vary on hourly and biweekly time scales. Spring and neap cycles cause variation in the strength of the tides, which drives variation in the mean river flows at which the Sacramento River reverses downstream of Georgiana Slough. For example, at a Freeport discharge of $7,500 \mathrm{ft}^{3} / \mathrm{s}$, the proportion of the day with reverse flow ranges from about 0.12 to 0.35 . Based on these considerations, if real-time operations are to be used to control flow reversals, we strongly encourage the development of explicit control rules for real-time management and testing of these controls through simulation models such as DSM2. 


\section{Corrections of Bias in Delta Simulation Model 2 Discharge Predictions at the Junction of the Sacramento River with the Delta Cross Channel and Georgiana Slough}

\section{Introduction}

We used the fish entrainment model described in Perry and others (2015) to simulate the probability of fish entering Georgiana Slough and the Delta Cross Channel under the California WaterFix scenarios simulated by Delta Simulation Model 2 (DSM2), a one dimensional hydrodynamic simulation model of the Delta (http://baydeltaoffice.water.ca.gov/modeling/deltamodeling/models/dsm2/dsm2.cfm). Because the model of Perry and others (2015) used USGS streamgage flows in the Sacramento River and Georgiana Slough to predict routing of juvenile salmon, we evaluated how well DSM2 predicted USGS streamgage flows. The concern was that bias in DSM2 flow predictions would induce bias in the predicted routing probabilities.

We noted evidence of bias when DSM2 flow predictions at USGS streamgages at Georgiana Slough near Sacramento River (GEO; USGS streamgage 11447903) and Sacramento River below Georgiana Slough (WGB; USGS streamgage 11447905) were compared to the measured flow data. Therefore, we used measured discharge data collected at these sites from November 2006 to December 2011 to correct discharge values predicted by DSM2. Discharge over this time period ranged from 8,440 to $21,000 \mathrm{ft}^{3} / \mathrm{s}$ at WGB and -534 to $8,300 \mathrm{ft}^{3} / \mathrm{s}$ at GEO. This range of flows covers the range of flows included in the Perry and others (2015) routing model that we applied to flows simulated by DSM2. However, the upper end of this range corresponds inflows to the Delta of about $41,000 \mathrm{ft}^{3} / \mathrm{s}$, as measured in the Sacramento River at Freeport, whereas inflows as simulated under the WaterFix scenarios extend to about $80,000 \mathrm{ft}^{3} / \mathrm{s}$. Therefore, we apply the routing model to DSM2 simulations where flows were less than $41,000 \mathrm{ft}^{3} / \mathrm{s}$.

Although DSM2 version 8.1.2 is the current release version, DSM2 simulations for the California WaterFix used DSM2 version 8.0.6 to maintain consistency with the simulations done under the Bay Delta Conservation Plan. Although not presented here, we determined that DSM2 version 8.1.2 showed less bias when used to predict discharge at these streamgages. By using measured flow data to correct DSM2 version 8.0.6 flow predictions, we minimized any potential bias in routing probabilities that would result from using biased flow predictions to predict routing probabilities. 


\section{Methods}

We developed two multiple linear regression models to predict measured flow at GEO and WGB as a function of DSM2 flows at Sacramento River above Delta Cross Channel (WGA; USGS streamgage 114479890), DCC (Delta Cross Channel), GEO, and WGB. First, we ran DSM2 to simulate the historical conditions during the periods for which we had measured flow data (November 2006December 2011; input files were obtained from http://baydeltaoffice.water.ca.gov/modeling/deltamodeling/models/dsm2v6/dsm2.cfm). Next, two indicator variables were constructed from the DSM2 simulations - (1) an indicator variable (IWGB) was used to provide the direction of flow at WGB (upstream flow $=1$, downstream flow $=0$ ) and (2), $\mathrm{DCC}_{\text {gate }}$ was used to indicate the status of the DCC gates (open=1, closed=0). Interactions between covariates also were included within the model. The model that resulted in the highest coefficient of determination $\left(\mathrm{R}^{2}\right)$ and that met all assumptions of linear regression (that is, homogeneity of residuals, low skew and kurtosis, etc.) was selected as the best-fit model. Lagged DSM2 flows were used to improve tidal phase shift. Alternative models were assessed to evaluate whether lagged flow variables improved model fit. Variables were lagged by 15 -min time steps from 15 to $150 \mathrm{~min}$.

\section{Results}

The best-fit model for the GEO streamgage included flow at all four streamgages (WGA, WGB, GEO, and DCC), lagged by two time steps or $30 \mathrm{~min}$ (table 2). The indicator variable IWGB and DCC gate position parameter (DCCgate) were included in the final model as main effects. The final model also included two- and three-way interactions. Two-way interactions included the interactions between lagged flow at each streamgage and DCC gate operation (DCCgate) and the interactions between lagged flow at each streamgage and the flow indicator parameter IwGB. The interaction between the indicator variable IWGB and DCC gate position also was retained in the final model. Three-way interactions consisted of the interactions between lagged flow at each streamgage, DCC gate position, and the flow indicator variable IwGB. The model fit the measured data reasonably well (fig. 16). Residuals between predicted and measured discharge at GEO were normally distributed and centered near $0 . \mathrm{R}^{2}$ was 0.949 .

The model for the WGB streamgage was similar to the model used to correct flows at GEO; however, flows were lagged by three time steps or 0.75 hour (that is, $\mathrm{Q}_{\mathrm{GEO}, 3}$; table 3 ). Discharge from all streamgages, the flow indicator parameter, and the $\mathrm{DCC}_{\text {gate }}$ indicator were included as main effects in the model (table 3). Two- and three-way interactions also were included in the final model. Two-way interactions retained in the final model consisted of the interactions between flow at each streamgage and DCC gate position. The interaction between flow at WGA, WGB, and GEO, and the flow indicator variable $\mathrm{I}_{\mathrm{WGB}}$ also was retained. The flow indicator variable that interacted with gate operations also was retained in the final model. Three-way interactions consisted of flow at WGA, WGB, and GEO that interacted with the DCC gate operations and the flow indicator parameter. The model provided a good fit to the data $\left(\mathrm{R}^{2}=0.962\right)$, and residuals between corrected flow and observed flow were normally distributed and had a mean of about 0 for all model fits (fig. 17). 
Table 2. Parameter estimates for correction of flow at Georgiana Slough near Sacramento River (GEO; U.S. Geological Survey streamgage 11447903), northern California.

[Parameters were lagged by two time steps or 30 minutes. Second subscript in each parameter indicates the number of lag steps. Q, discharge; GEO, Georgiana Slough; WGB, Sacramento River below Georgiana Slough; WGA, Sacramento River above Walnut Grove; DCCgate, indicator variable for position of the Delta Cross Channel gate position $(1=$ open, $0=$ closed); I, indicator variable for flow direction at WGB ( 1 = upstream, $0=$ downstream)]

\begin{tabular}{|c|c|c|c|}
\hline & Parameter & Estimate & $\begin{array}{l}\text { Standard } \\
\text { error }\end{array}$ \\
\hline \multirow[t]{7}{*}{ Main effects } & (Intercept) & -81.800 & 4.616 \\
\hline & $\mathrm{Q}_{\mathrm{GEO}, 2}$ & 0.568 & 0.009 \\
\hline & $\mathrm{Q}_{\mathrm{WGB}, 2}$ & -0.099 & 0.007 \\
\hline & $\mathrm{QWGA}, 2_{\mathrm{W}}$ & 0.238 & 0.007 \\
\hline & $\mathrm{QDCC}, 2_{2}$ & -0.152 & 0.010 \\
\hline & $\mathrm{I}_{\mathrm{WGB}}$ & 894.100 & 21.910 \\
\hline & DCCgate & 219.600 & 8.072 \\
\hline \multirow[t]{9}{*}{ Two-way interactions } & $\mathrm{Q}_{\mathrm{GEO}, 2} \times$ DCCgate & -0.731 & 0.016 \\
\hline & $\mathrm{Q}_{\mathrm{WGB}, 2} \times$ DCCgate & -0.296 & 0.011 \\
\hline & $\mathrm{Q}_{\mathrm{WGA}, 2} \times$ DCCgate & 0.330 & 0.012 \\
\hline & QDCC, $2 \times$ DCCgate & -0.195 & 0.014 \\
\hline & $\mathrm{I}_{\mathrm{WGB}} \times$ DCCgate & -483.200 & 24.150 \\
\hline & $\mathrm{Q}_{\mathrm{GEO}, 2} \times \mathrm{I}_{\mathrm{WGB}}$ & -0.148 & 0.026 \\
\hline & $\mathrm{Q}_{\mathrm{WGB}, 2} \times \mathrm{I}_{\mathrm{WGB}}$ & -0.050 & 0.020 \\
\hline & $\mathrm{Q}_{\mathrm{WGA}, 2} \times \mathrm{I}_{\mathrm{WGB}}$ & -0.015 & 0.022 \\
\hline & $\mathrm{Q}_{\mathrm{DCC}, 2} \times \mathrm{I}_{\mathrm{WGB}}$ & -0.111 & 0.024 \\
\hline \multirow[t]{4}{*}{ Three-way interactions } & $\mathrm{Q}_{\mathrm{GEO}, 2} \times \mathrm{I}_{\mathrm{WGB}} *$ DCCgate & 0.220 & 0.032 \\
\hline & $\mathrm{Q}_{\mathrm{WGB}, 2} \times \mathrm{I}_{\mathrm{WGB}} *$ DCCgate & 0.203 & 0.023 \\
\hline & $\mathrm{Q}_{\mathrm{WGA}, 2} \times \mathrm{I}_{\mathrm{WGB}} *$ DCCgate & -0.209 & 0.025 \\
\hline & $\mathrm{Q}_{\mathrm{DCC}, 2} \times \mathrm{I}_{\mathrm{WGB}} *$ DCCgate & 0.333 & 0.027 \\
\hline
\end{tabular}



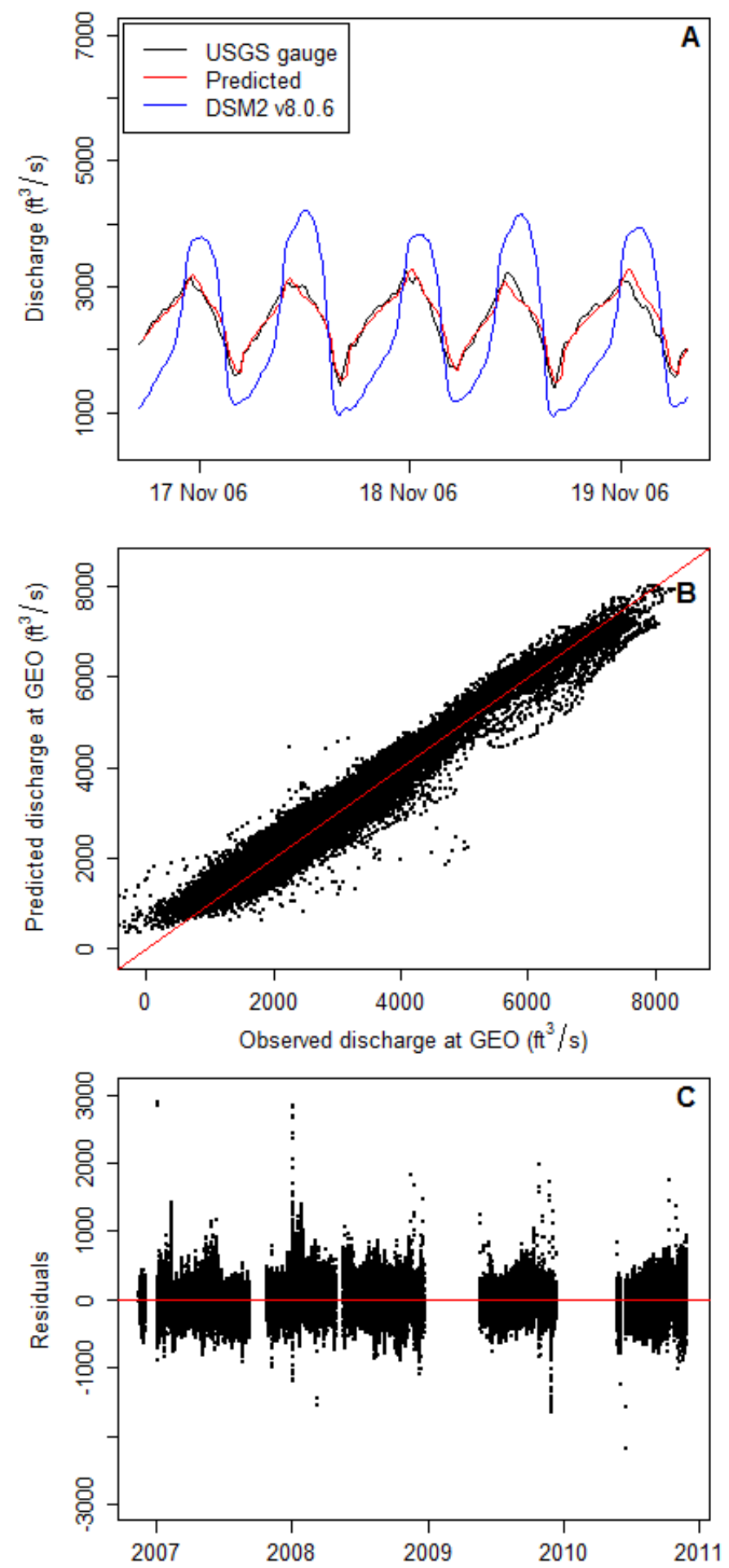

Figure 16. Graphs showing (A) comparison of observed (i.e., measured) (Delta Simulation Model 2, version 8.0.6 [DSM2 v8.0.6]) and regression-corrected (predicted) discharge, during November 17-19, 2006; (B) comparison of observed and predicted discharge; and (C) residuals of predicted and observed discharge during 2007-11, at the Georgiana Slough near Sacramento River (GEO; U.S. Geological Survey [USGS] streamgage 11447903), northern California. Diagonal red line in graph (B) shows where observed discharge equals predicted discharge. The horizontal red line in graph $(\mathrm{C})$ shows where residuals are zero. $\mathrm{ft}^{3} / \mathrm{s}$, cubic foot per second. 
Table 3. Parameter estimates for correcting Delta Simulation Model 2, version 8.0.6, predicted flow at Sacramento River below Georgiana Slough (WGB; U.S. Geological Survey streamgage 11447905), northern California.

[Parameters were lagged by three time steps or 0.75 hour. Second subscript in each parameter indicates the number of lag steps. Q, discharge; GEO, Georgiana Slough; WGB, Sacramento River below Walnut Grove; WGA, Sacramento River above Walnut Grove; DCCgate, indicator variable for position of the Delta Cross Channel gate position $(1=$ open, $0=$ closed); I, indicator variable for flow direction at WGB (1 = upstream, $0=$ downstream $)]$

\begin{tabular}{|c|c|c|c|}
\hline & Parameter & Estimate & $\begin{array}{c}\text { Standard } \\
\text { error }\end{array}$ \\
\hline \multirow[t]{7}{*}{ Main effects } & (Intercept) & -2317 & 22 \\
\hline & $\mathrm{Q}_{\mathrm{GEO}, 3}$ & 2.326 & 0.039 \\
\hline & QwGB,3 & 2.173 & 0.030 \\
\hline & QwGA,3 & -1.283 & 0.033 \\
\hline & $\mathrm{I}_{\mathrm{WGB}, 3}$ & 1392 & 87 \\
\hline & DCCgate, 3 & 722 & 38 \\
\hline & $\mathrm{QDCC}, 3_{3}$ & 1.447 & 0.042 \\
\hline \multirow[t]{8}{*}{ Two-way interactions } & $\mathrm{Q}_{\mathrm{GEO}, 3} \times$ DCCgate, 3 & 0.678 & 0.065 \\
\hline & $\mathrm{QWGB}, 3 \times$ DCCgate, 3 & 1.002 & 0.042 \\
\hline & $\mathrm{Q}_{\mathrm{WGA}, 3} \times$ DCCgate,3 & -1.055 & 0.045 \\
\hline & $\mathrm{I}_{\mathrm{WGB}} \times$ DCCgate, 3 & -394 & 99 \\
\hline & $\mathrm{Q}_{\mathrm{GEO}, 3} \times \mathrm{I}_{\mathrm{WGB}, 3}$ & -0.314 & 0.052 \\
\hline & $\mathrm{QWGB}, 3_{\mathrm{W}} \times \mathrm{I}_{\mathrm{WGB}, 3}$ & 0.017 & 0.038 \\
\hline & $\mathrm{QWGA}, 3_{\mathrm{W}} \times \mathrm{I}_{\mathrm{WGB}, 3}$ & -0.349 & 0.041 \\
\hline & QDCC, $3 \times$ DCCgate, 3 & 1.219 & 0.051 \\
\hline \multirow[t]{3}{*}{ Three-way interactions } & $\mathrm{Q}_{\mathrm{GEO}, 3} \times \mathrm{I}_{\mathrm{WGB}} *$ DCCgate, 3 & -0.491 & 0.082 \\
\hline & $\mathrm{QWGB}, 3_{\mathrm{W}} \times \mathrm{I}_{\mathrm{WGB}} *$ DCCgate, 3 & -0.263 & 0.042 \\
\hline & $\mathrm{QWGA}, 3 \times \mathrm{I}_{\mathrm{WGB}} * \mathrm{DCC}$ gate, 3 & 0.256 & 0.045 \\
\hline
\end{tabular}



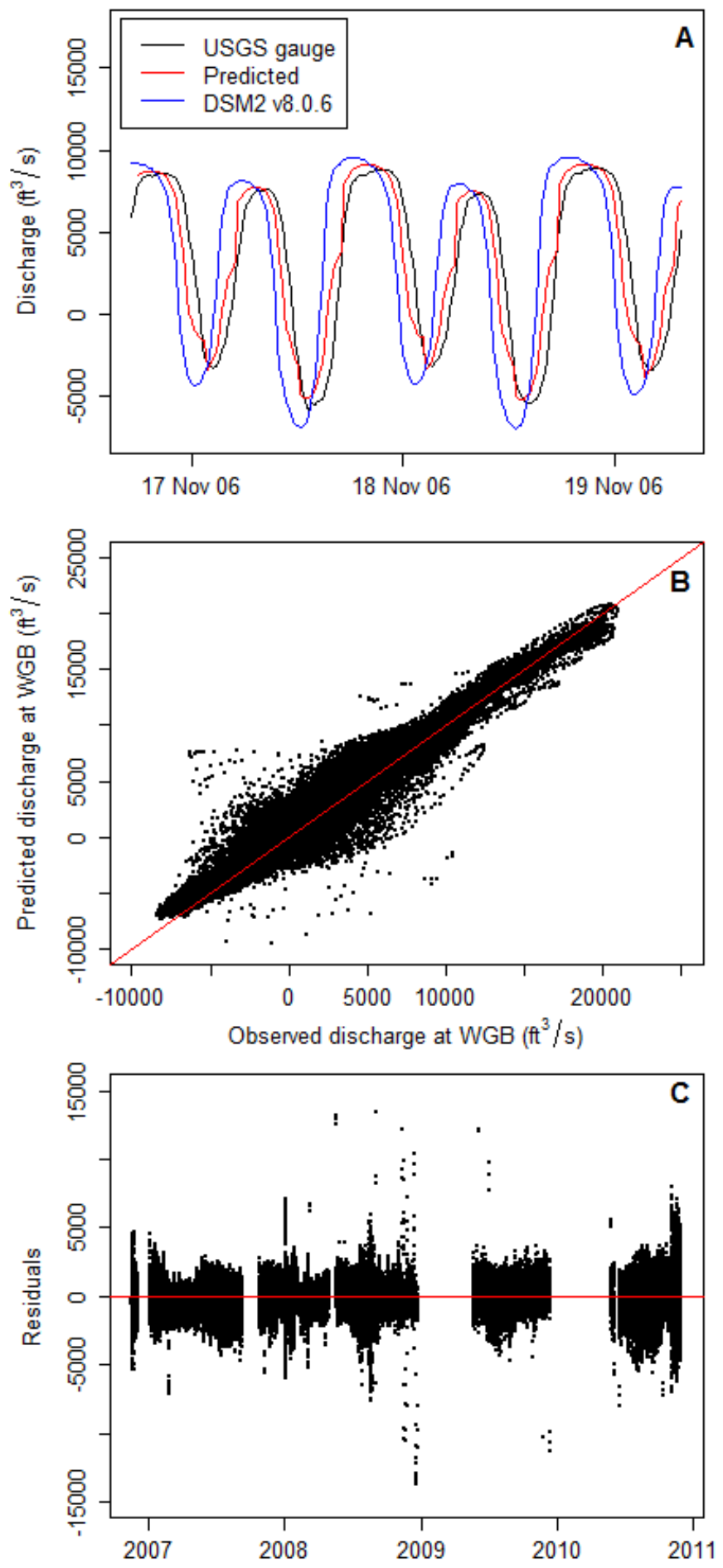

Figure 17. Graphs showing (A) comparison of observed (Delta Simulation Model 2, version 8.0.6 [DSM2 v8.0.6], and regression-corrected (predicted) discharge, during November 17-19, 2006; (B) comparison of observed and predicted discharge; and (C) residuals of the predicted and measured discharge during 2007-11, at the Sacramento River below Georgiana Slough (WGB; U.S. Geological Survey streamgage 11447905), northern California. Diagonal line in graph (B) has slope of 1 and an intercept of 0 . Diagonal red line in graph (B) shows where observed discharge equals predicted discharge. The horizontal red line in graph $(\mathrm{C})$ shows where residuals are zero. $\mathrm{ft}^{3} / \mathrm{s}$, cubic foot per second $\mathrm{ft}^{3} / \mathrm{s}$, cubic foot per second. 


\section{Discussion}

We used lagged flow variables in conjunction with indicator variables to create models to adjust DSM2 predicted flows at both GEO and WGB. Our models provide a good adjustment for correcting the DSM2 output; however, the predictive power of our model is limited to the range of flows used for the correction. Empirical data were only available for 2006-11. Therefore, one should use caution in applying the model to predict flows outside of range of flows used in the model development.

Lags in the model covariates improved model fits, suggesting that DSM2 version 8.0.6 does not adequately predict tidal phasing at this location. Given the time lags, it seems that DSM2 is predicting water pulses to arrive later than measured at WGB and earlier than measured at GEO. Additionally, DSM2 routinely overestimated the magnitude of flow at WGB. In contrast, DSM2 accurately estimated the magnitude of flow at GEO. This suggests that the complex hydrodynamics at this junction are not fully captured by DSM2. 


\section{Simulation of Effects of the North Delta Diversion on Daily Entrainment Probability of Juvenile Chinook Salmon into Georgiana Slough and the Delta Cross Channel}

\section{Introduction}

This analysis investigates the effect of the proposed North Delta Diversion (NDD) on entrainment of juvenile Chinook salmon (Oncorhynchus tshawytscha) into Georgiana Slough and the Delta Cross Channel (DCC). Specifically, we used the entrainment probability model of Perry and others (2015) to predict entrainment probabilities from flows simulated by Delta Simulation Model 2 (DSM2) under the California WaterFix No Action Alternative (NAA, no diversion implemented) and Proposed Action (PA, diversion implemented) from October to June for each water year ${ }^{1}$ in the 82 -year simulation period (ICF International, 2016). The entrainment model is based on a multinomial regression analysis that estimated the probability $(\pi)$ of individual fish entering the DCC $\left(\pi_{\mathrm{DCC}}\right)$, Georgiana Slough ( $\left.\pi_{\mathrm{GEO}}\right)$, and the Sacramento River $\left(\pi_{\mathrm{SAC}}\right)$ from three variables: (1) Instantaneous river discharge (that is, measured every $15 \mathrm{~min}$ ) entering Georgiana Slough (GEO), (2) instantaneous discharge of the Sacramento River below Georgiana Slough (WGB), and (3) DCC gate position (1 = open, $0=$ closed). The entrainment model was based on acoustic telemetry data collected between 2006 and 2009 from 919 juvenile late-fall Chinook salmon that passed the river junction over river flows of the Sacramento River at Freeport ranging from $6,802 \mathrm{ft}^{3} / \mathrm{s}$ to $40,700 \mathrm{ft}^{3} / \mathrm{s}$. A complete description of the model, including model equations, estimated parameters, and goodness-of-fit, is available in Perry and others (2015) and Perry (2010).

\section{Methods}

To apply the entrainment model of Perry and others (2015) to DSM2 output, we (1) corrected DSM2 discharge simulations at WGB and GEO using the regression correction described in the previous section, (2) formed covariates required for the entrainment model from the corrected DSM2 discharge simulations, and (3) simulated route entrainment probabilities for the entire 82-year time series of 15-min flows simulated under the NAA and PA scenarios. We then tabulated daily entrainment probabilities as the mean of 15 -min entrainment probabilities for each day. Daily entrainment probabilities represent the expected fraction of fish entering each channel on a particular date under the assumption that fish migrate past this river junction uniformly over the diel period. Although nocturnal migration has been documented for late-fall run Chinook salmon (Chapman and other, 2013), we used a uniform distribution because diel activity patterns can vary considerably with environmental variables and species (Bradford and others, 2001). As a sensitivity analysis, we compared differences between scenarios for day and night entrainment (appendix 1, figs. 1.1 and 1.2).

\footnotetext{
${ }^{1}$ The 12-month period from October 1, for any given year, through September 30, of the following year. The water year is designated by the calendar year in which it ends.
} 
The entrainment model was based on data collected at a maximum Freeport discharge of 40,700 $\mathrm{ft}^{3} / \mathrm{s}$, whereas the DSM2 simulations include Freeport flows of as much as about $80,000 \mathrm{ft}^{3} / \mathrm{s}$. Therefore, we evaluated the behavior of the model at flows greater than $40,000 \mathrm{ft}^{3} / \mathrm{s}$ because we were concerned about using the entrainment model outside the range of data used to inform the model. Simulated daily entrainment probabilities based on DSM2 output increased from about 0.35 to 0.50 as Freeport discharge increased from about $40,000 \mathrm{ft}^{3} / \mathrm{s}$ to $80,000 \mathrm{ft}^{3} / \mathrm{s}$ (fig. 18). We compared these predictions to estimates from Perry and others (2014), who quantified the effect of a non-physical barrier on entrainment into Georgiana Slough when Freeport flows were about $80,000 \mathrm{ft}^{3} / \mathrm{s}$. At this flow level, Perry and others (2014) estimated a mean entrainment probability into Georgiana Slough of about 0.30 with the non-physical barrier off, compared to 0.50 simulated using the Perry and others (2015) model. This finding suggests that entrainment probabilities remain relatively constant at flows between 40,000 $\mathrm{ft}^{3} / \mathrm{s}$ and $80,000 \mathrm{ft}^{3} / \mathrm{s}$ rather than increasing as the model of Perry and others (2015) would predict. Because the Perry and others (2015) model seems to overestimate entrainment at high flows, we restricted our analysis of simulated daily entrainment probabilities to flows at Freeport of 41,000 ft $3 / \mathrm{s}$ or greater.

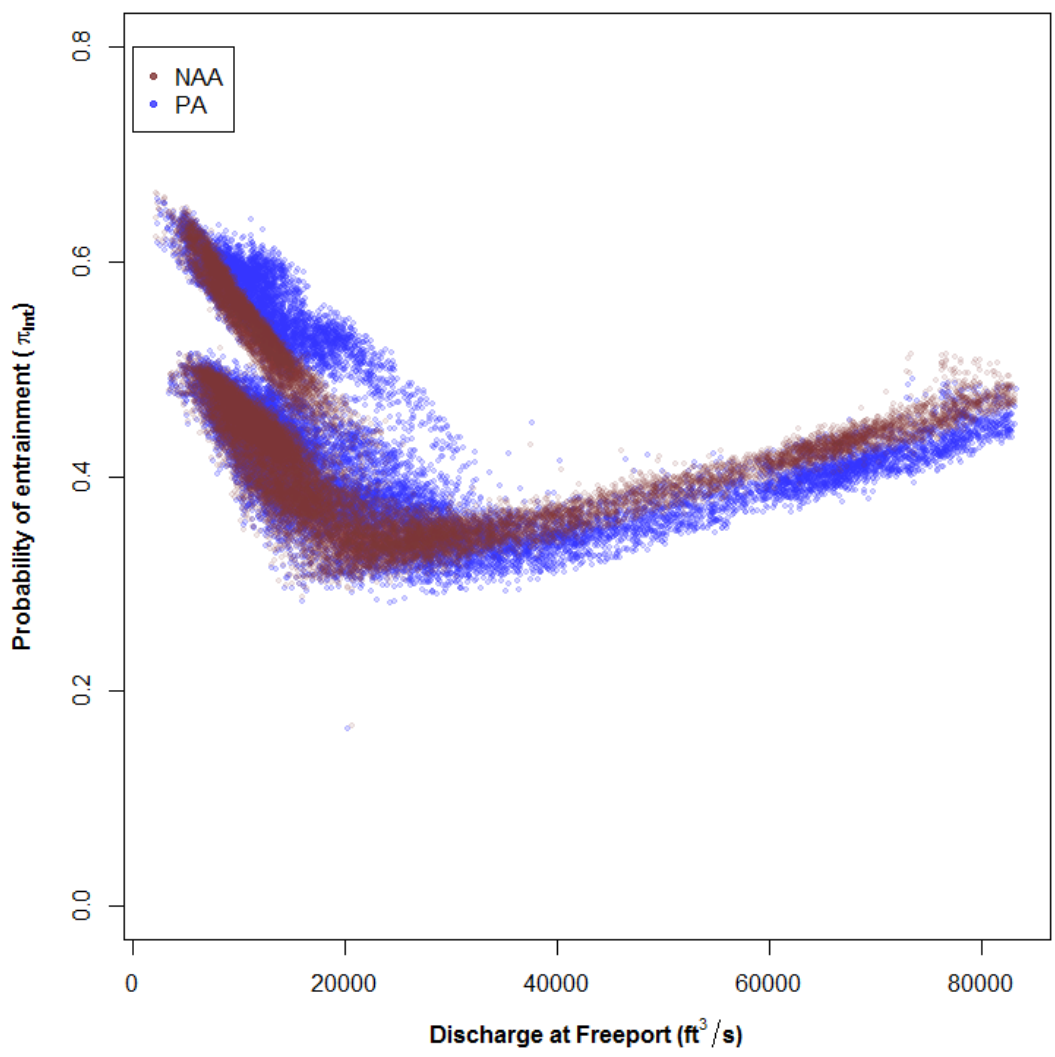

Figure 18. Graph showing daily probability of juvenile Chinook salmon (Oncorhynchus tshawytscha) entering the interior Sacramento-San Joaquin River Delta $\left(\pi_{\mathrm{nt}}=\pi_{\mathrm{GEO}}+\pi_{\mathrm{DCC}}\right)$ as a function of Sacramento River discharge at Freeport (FPT; USGS streamgage 11447650) for the No Action Alternative (NAA) and Proposed Action (PA) simulations done using Delta Simulation Model 2, northern California. $\pi$ nt , probability of juvenile Chinook salmon entering the interior Delta; $\pi_{G \in O}$, probability of juvenile Chinook salmon entering Georgiana Slough]; $\pi \mathrm{DCc}$, probability of juvenile Chinook salmon entering Sacramento River. 
Ideally, if daily inflows to the Delta were the same between NAA and PA scenarios, then daily entrainment probabilities could be compared directly among common dates using different management alternatives between scenarios. However, daily inflows to the Delta vary between scenarios owing to upstream flow management that differs between scenarios, making direct comparison of daily entrainment probabilities problematic. Therefore, we compared scenarios by summarizing daily entrainment probabilities within each year by averaging daily entrainment probabilities over (1) each year, (2) each month within years, and (3) over three alternative run-timing distributions. Summary statistics included days when Freeport flows were less than or equal to 41,000 $\mathrm{ft}^{3} / \mathrm{s}$ and excluded days when flows were $>41,000 \mathrm{ft}^{3} / \mathrm{s}$. The three run-timing scenarios were (1) a uniform distribution, where an equal proportion of fish out-migrated on each day of each month; (2) an early-run timing representing winter-run Chinook in years when flow conditions trigger an early migration into the Delta, and (3) a late-run timing representing winter-run Chinook in years when the migration begins in December (fig. 19). Estimates of annual entrainment probability for the different run timings were calculated as a weighted average of the daily entrainment probability weighted by the proportion of the run migrating on a given day (assuming an equal migration on each day of a given month). Run-timing distributions were based on winter-run-sized juvenile Chinook rotary screw trapping data from Knights Landing (Yvette Redler, National Marine Fisheries Service, written commun., January 7, 2016). We then categorized these annual statistics according to California Department of Water Resources water-year classification and compared box plots of annual entrainment probabilities for different water year types. California Department of Water Resources uses five classifications for water year type in the Sacramento Valley that are based on water year index value (WYI) in millions of acre-feet (MAF):

1. $\mathrm{W}=\mathrm{Wet}, \mathrm{W} Y \mathrm{I} \geq 9.2$;

2. $\mathrm{AN}=$ Above Normal, $7.8 \leq \mathrm{WYI} \leq 9.2$;

3. $\mathrm{BN}=$ Below Normal, $6.5 \leq \mathrm{WYI} \leq 7.8$;

4. $\mathrm{D}=$ Dry, $5.4 \leq \mathrm{WYI} \leq 6.5$; and

5. $\mathrm{C}=$ Critical, $\mathrm{WYI} \leq 5.4$ (Kapahi and others, 2006). 


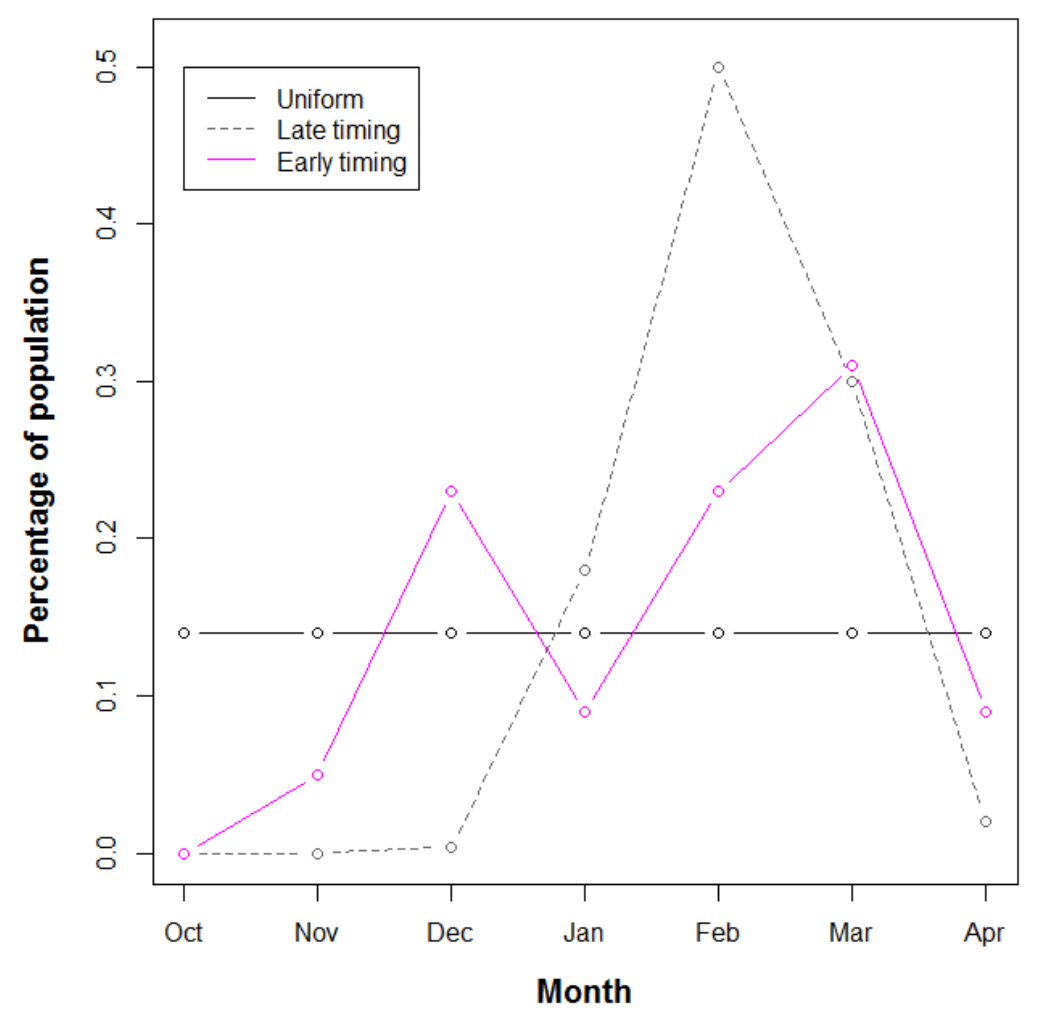

Figure 19. Graph showing run-timing scenarios used to estimate mean annual entrainment probabilities, with the early and late timings representing two scenarios for winter-run Chinook salmon in the Sacramento River, northern California, October-April.

\section{Results}

We estimated entrainment probabilities for NAA and PA under three run-timing distributions over an 82-year period. The mean annual entrainment probabilities generally differed little between NAA and PA (table 4); however, we noted small but consistent differences in entrainment between scenarios that varied across years (figs. 20-23). For example, under uniform run timing, the annual probability of fish remaining in the Sacramento River for the PA scenario was 0-4 percent lower than under the NAA scenario, indicating higher entrainment into the interior Delta (fig. 20). Mean annual entrainment into the DCC was consistently higher under the PA scenario, but differences in mean annual entrainment into Georgiana Slough indicated both positive and negative deviations (fig. 20). These findings indicate that the increased entrainment into the DCC was largely responsible for the lower probability of fish remaining in the Sacramento River. 
Table 4. Mean predicted annual entrainment probabilities (with standard deviations in parentheses) under different run-timing scenarios for No Action Alternative (NAA) and Proposed Action (PA) simulations done using Delta Simulation Model 2, Sacramento-San Joaquin River Delta, northern California.

\begin{tabular}{lcc|ll|ll}
\hline \multirow{2}{*}{$\begin{array}{c}\text { Run-timing } \\
\text { scenarios }\end{array}$} & \multicolumn{2}{c|}{ Sacramento River } & \multicolumn{2}{c|}{ Georgiana Slough } & \multicolumn{2}{c}{ Delta Cross Channel } \\
\cline { 2 - 7 } & \multicolumn{1}{c}{ NAA } & \multicolumn{1}{c|}{ PA } & \multicolumn{1}{c}{ NAA } & \multicolumn{1}{c}{ PA } & \multicolumn{1}{c}{ NAA } & \multicolumn{1}{c}{ PA } \\
\hline Uniform & $0.571(0.031)$ & $0.556(0.028)$ & $0.349(0.017)$ & $0.346(0.017)$ & $0.072(0.03)$ & $0.089(0.024)$ \\
Late & $0.555(0.132)$ & $0.547(0.129)$ & $0.344(0.09)$ & $0.352(0.094)$ & $0(0)$ & $0(0)$ \\
Early & $0.558(0.085)$ & $0.549(0.082)$ & $0.346(0.061)$ & $0.352(0.063)$ & $0.018(0.018)$ & $0.021(0.018)$ \\
\hline
\end{tabular}

The differences in entrainment between PA and NAA under the early run timing indicated a slightly higher (by about 1 percentage point) mean annual probability of entering the DCC (fig. 21). However, for the late run timing, we noted little difference in entrainment between the NAA and PA scenarios, and the proportion entrained into the DCC was very low because of little overlap between the late run timing and DCC operation (fig. 21). The differences in annual entrainment among the run timing scenarios suggested that daily entrainment probabilities varied seasonally, thereby affecting annual entrainment differentially for the alternative run timings.

Examination of the distribution of mean monthly entrainment probabilities indicated seasonal patterns that varied among water year types (fig. 22). In all but critically dry years, median $\pi_{\mathrm{SAC}}$ (the probability of fish remaining in the Sacramento River) under the PA scenario was as much as 5 percentage points lower than under the NAA scenario for October and November (fig. 22). This difference also was apparent for June in wet years. Because the early and late run timings had 0 probability of migrating in October and low (early) or 0 (late) probability of migrating in November, these run-timing distributions had little exposure to the differences in operation between PA and NAA during these months, leading to little difference in mean annual entrainment probabilities (figs. 20 and 21).

For the months of October, November, and June, fish had a lower probability of remaining in the Sacramento River owing primarily to a higher probability of entering the DCC. This occurred because the DCC gates were open more frequently in October and November (fig. 23), which contributed to the higher mean monthly probability of entering the DCC. For example, we identified days when the DCC was open under PA but closed under NAA (fig. 24). Under NAA, the DCC remained closed owing to NDD Bypass flows $>25,000 \mathrm{ft}^{3} / \mathrm{s}$, a trigger that causes closure of the DCC in order to limit the potential for flooding and scour at the facility (fig. 24G). However, under PA, water diversion reduced bypass flows to less than $25,000 \mathrm{ft}^{3} / \mathrm{s}$, which allowed the DCC gates to remain open (fig. 24). In turn, opening the DCC gates substantially reduced the instantaneous probability of fish remaining in the Sacramento River by increasing the probability of fish entering the DCC (fig. 24). 

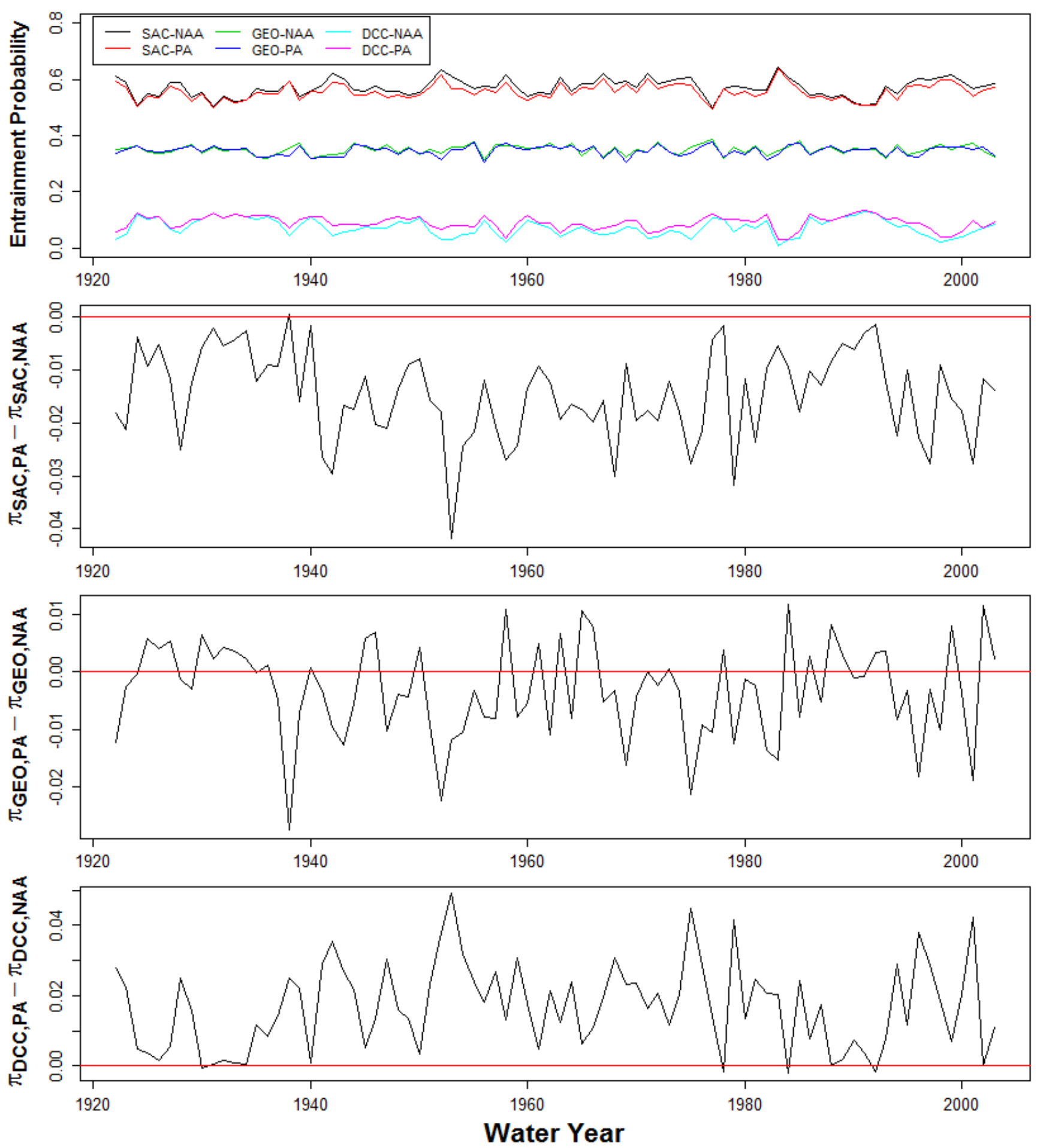

Figure 20. Graphs showing comparison of predicted mean annual juvenile Chinook salmon entrainment probability $(\pi)$ assuming uniform run timing for the Sacramento River (SAC), Georgiana Slough (GEO), and Delta Cross Channel (DCC) between the Proposed Action (PA) and No Action Alternative (NAA), Sacramento-San Joaquin River Delta, northern California, water years 1922-2003. Mean annual entrainment probabilities (top graph) and the difference in entrainment between scenarios for SAC, GEO, and DCC (bottom three graphs, respectively) are shown. Values above horizontal red line indicate greater entrainment under the PA scenario. 

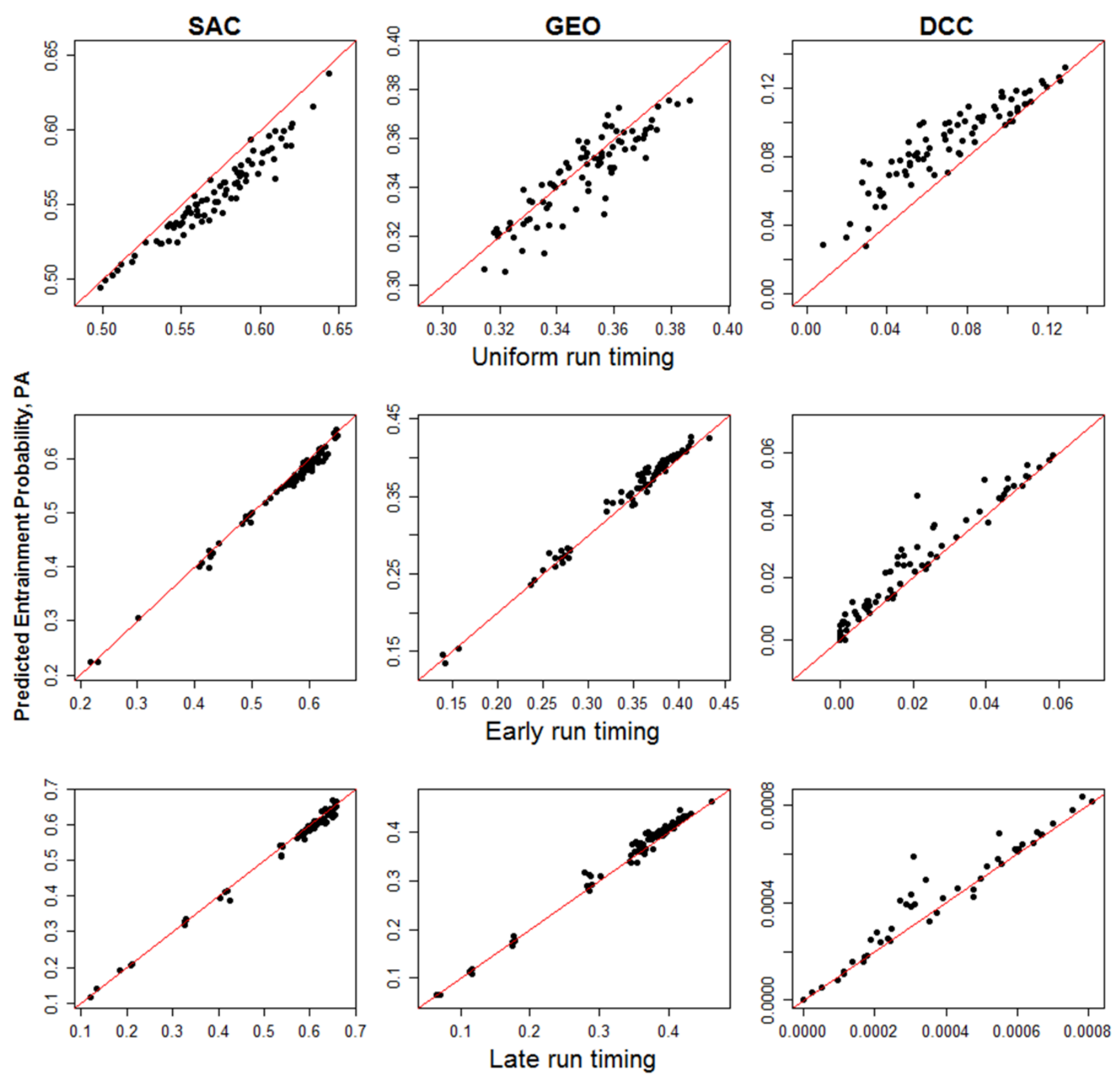

Predicted Entrainment Probability, NAA

Figure 21. Graphs showing comparison of predicted mean entrainment probability for the Sacramento River (SAC), Georgiana Slough (GEO), and Delta Cross Channel (DCC) between the Proposed Action (PA) and No Action Alternative (NAA) for uniform arrival and two different run timings for winter-run Chinook salmon, Sacramento-San Joaquin River Delta, northern California. Data points (black dots) are paired by year, and diagonal line has slope of 1 and an intercept of 0. 

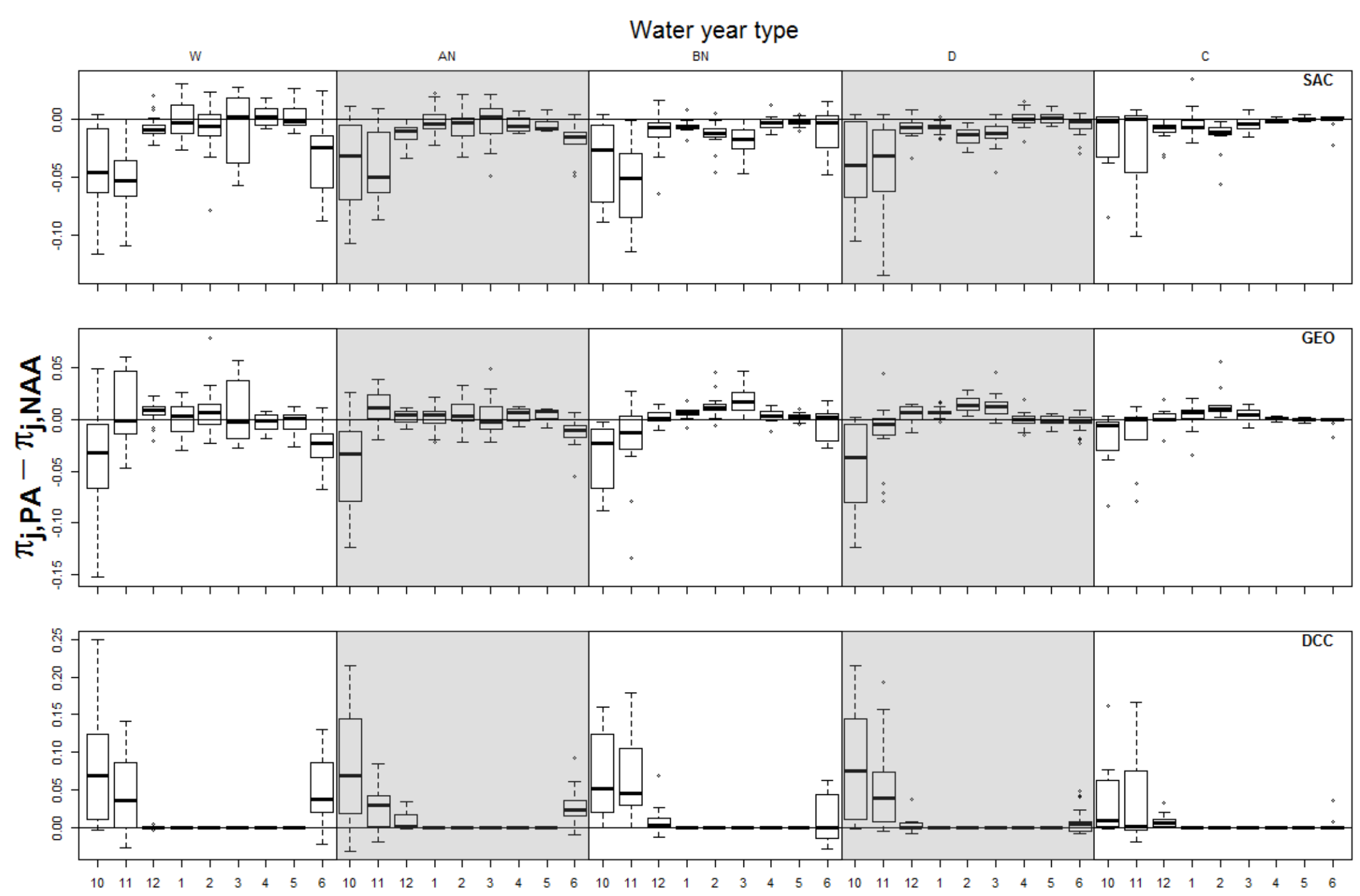

Figure 22. Boxplots showing differences in predicted juvenile Chinook salmon entrainment probability between the Proposed Action (PA) and No Action Alternative (NAA) $(\pi, \mathrm{PA}-\pi$, NAA) by water year type and month assuming a uniform run timing (W=Wet, $A N=A b o v e ~ N o r m a l, ~ B N=B e l o w$ Normal, $D=D r y, C=C r i t i c a l)$, Sacramento-San Joaquin River Delta, northern California, October-June (x-axis labels showing month of year). Boxes range from the 25 th to the 75 th percentiles with a line indicating the median, whiskers extend 1.5 times past the length of the box, and dots represent data points beyond the whiskers. 
Water year type
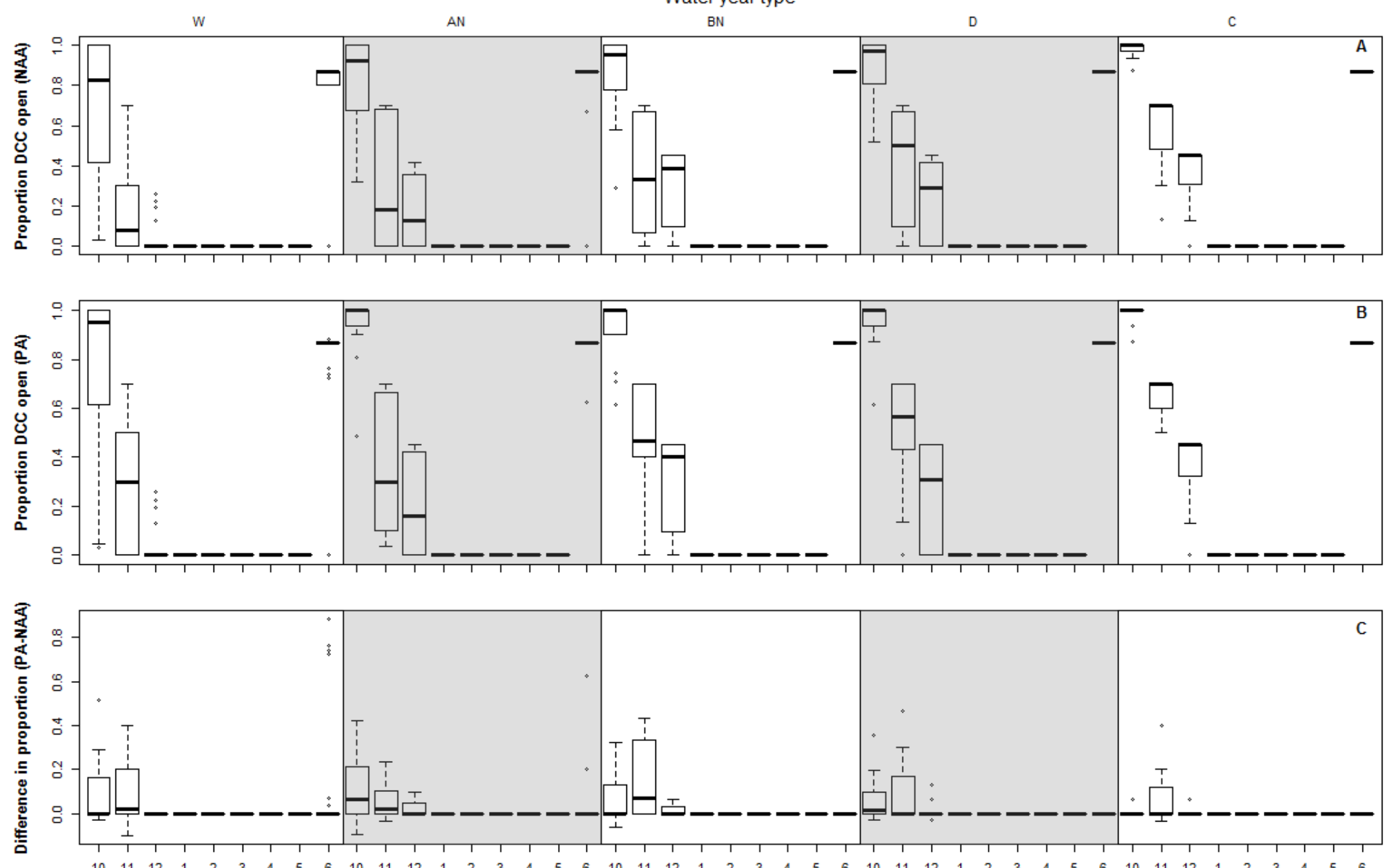

Figure 23. Boxplots showing proportion of each month that the Delta Cross Channel (DCC) was open for the No Action Alternative (NAA, boxplots in panel A), Proposed Action (PA, boxplots in panel B), and the difference between PA and NAA (boxplots in panel C) by water year type (W=Wet,

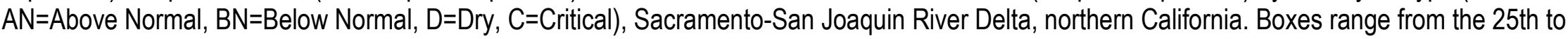
the 75th percentiles with a line indicating the median, whiskers extend 1.5 times past the length of the box, and dots represent data points beyond the whiskers. 

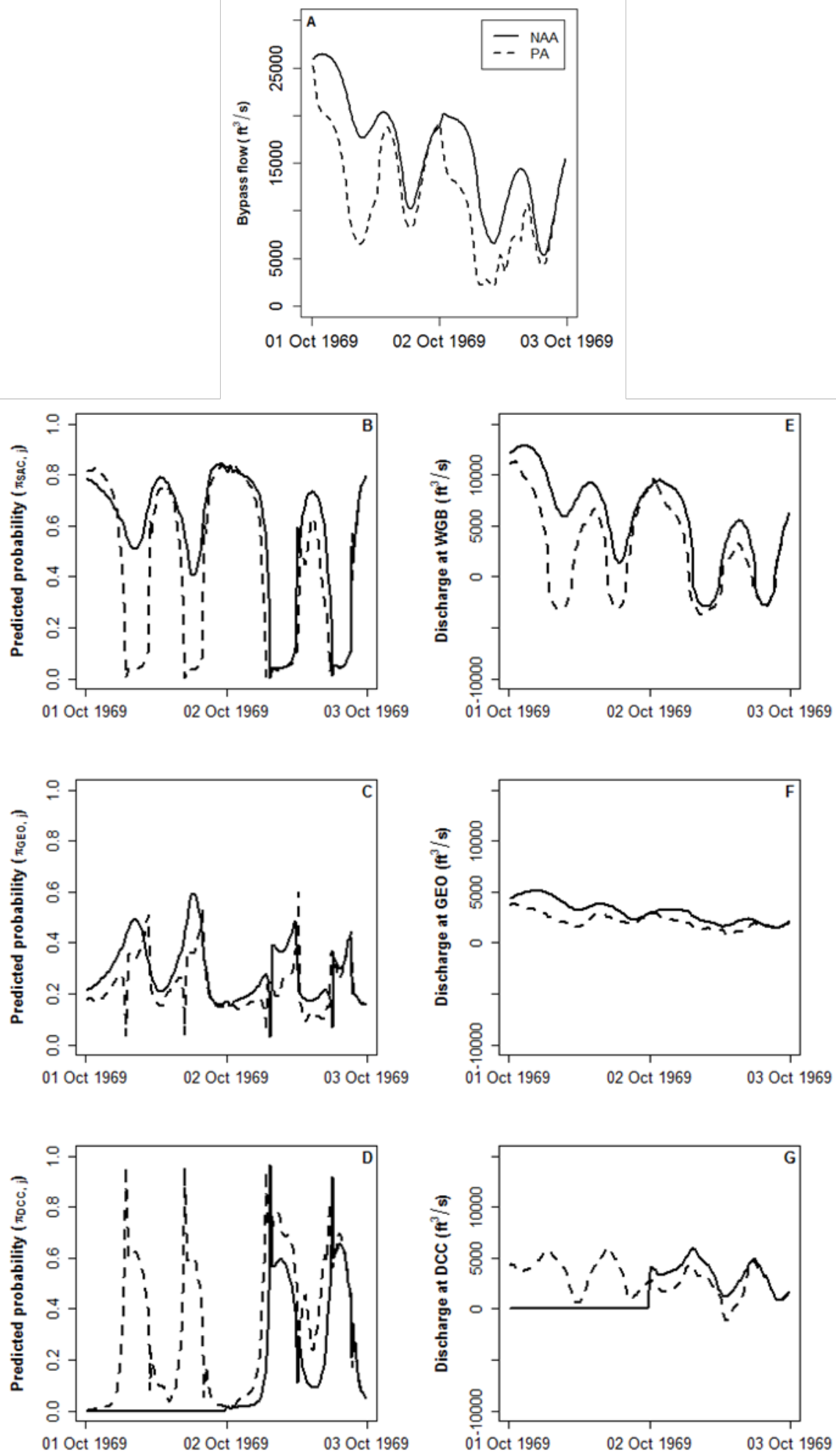

Figure 24. Graphs showing comparison of bypass flows (A) and predicted probability of juvenile Chinook salmon entrainment $(\pi)$ into Sacramento River (WGB) (B), Georgiana Slough (GEO) (C), and the Delta Cross Channel (DCC) (D) for the Proposed Action (PA) and No Action Alternative (NAA) when the DCC was open under PA but closed under NAA, Sacramento-San Joaquin River Delta, northern California, October 1-3, 1969. Discharges (in cubic feet per second $\left[{ }^{3} / \mathrm{s}\right]$ ) entering each route for NAA and PA also are shown graphs $E$, $F$, and $G$. 
We determined that much of the interannual variation in mean annual entrainment probabilities could be attributed to water year classification. For example, mean annual $\pi_{\mathrm{SAC}}$ for the uniform run timing decreased from a median of about 0.60 to 0.52 as water year type transitioned from wet to critically dry years (fig. 25 ). In contrast, mean annual $\pi_{\mathrm{GEO}}$ and $\pi_{\mathrm{DCC}}$ increased as water years transitioned from wet to critically dry (fig. 25). Between scenarios, $\pi_{\mathrm{SAC}}$ under PA was less than under the NAA scenario for all water year types for a uniform run timing (fig. 26). For the early and late run timings, we observed little difference between PA and NAA for $\pi_{\mathrm{SAC}}$ for wet and above normal water years, but $\pi_{\mathrm{SAC}}$ was consistently lower than the other locations for PA relative to NAA (fig. 26). Although we noted some consistent differences between PA and NAA among water year types, the median difference between scenarios was $<2$ percentage points for all mean annual entrainment probabilities.

\section{Discussion}

We used previously developed entrainment models to predict the probability of fish entrainment into the interior Delta through Georgiana Slough and the DCC under the PA and NAA scenarios for different run timings and water year types. Overall, the probability of remaining in the Sacramento River was lower under the PA scenario, but the magnitude of the difference was small. However, when run timing was assumed to occur between December and April, this difference was even less because fish were less exposed to periods when we observed the largest difference in entrainment between scenarios (October and November).

Although we observed relatively small differences in entrainment, we restricted our analysis to flows $<41,000 \mathrm{ft}^{3} / \mathrm{s}$ to avoid potential bias in predicted entrainment probabilities at higher flows. When the entrainment model of Perry and others (2015) was used to predict entrainment at higher flows, the model predicted that entrainment increased with increasing river flow to as much as about 50-percent entrainment at flows of $80,000 \mathrm{ft}^{3} / \mathrm{s}$ at Freeport (fig. 18). However, comparison to estimates of entrainment from Perry and others (2014) at similar flows indicated entrainment into Georgiana Slough of only about 30 percent. The entrainment model was fit to data that encompassed the range of flows where the Sacramento River transitions from strongly reversing to non-reversing flows. Thus, the parameterization of the model captured changes in entrainment owing to the strength of reversing flows, and indicated that highest entrainment occurred at the lowest flows where tidal forcing increased the magnitude and duration of reverse flows. The available empirical evidence suggests that entrainment stabilizes as inflows increase above the level at which reverse flows cease, but more data is needed to substantiate this observation. Assuming that this pattern holds true, excluding the highflow observations from our analysis would tend to weight the mean annual entrainment probabilities more towards the higher daily entrainment probabilities that occur at lower discharges. Therefore, we may have observed even less difference in mean annual entrainment probabilities between PA and NAA had we used a model that predicted that daily entrainment probabilities are relatively constant at flows $>41,000 \mathrm{ft}^{3} / \mathrm{s}$. 

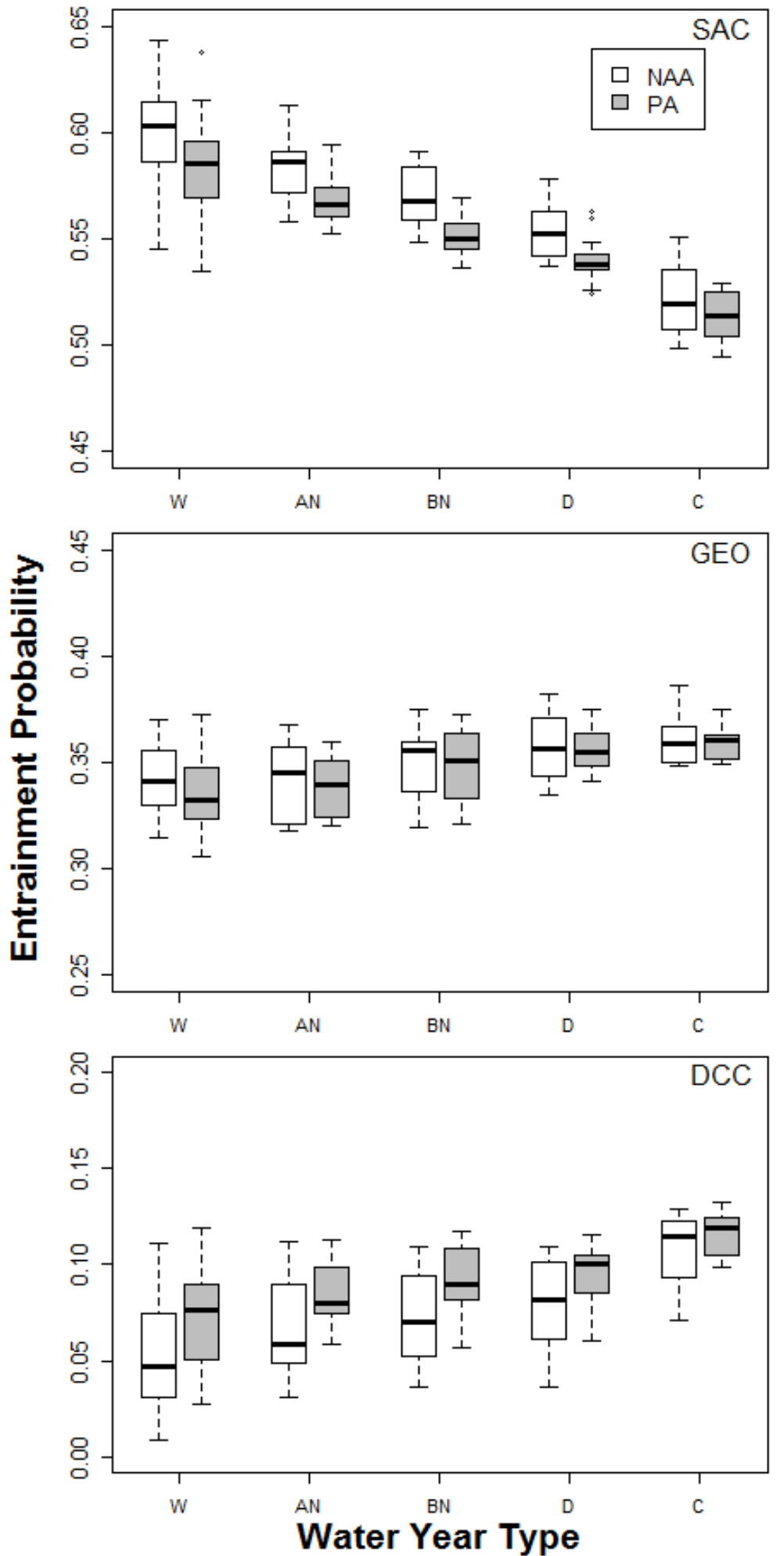

Figure 25. Boxplots showing predicted mean annual probability of juvenile Chinook salmon entrainment for the Sacramento River (SAC), Georgiana Slough (GEO), and Delta Cross Channel (DCC) between the No Action Alternative (NAA) and Proposed Action (PA) by water year type based on a uniform run-timing distribution $(\mathrm{W}=$ Wet, $A N=$ Above Normal, BN=Below Normal, $D=$ Dry, $C=C r i t i c a l)$, Sacramento-San Joaquin River Delta, northern California. Boxes range from the 25th to the 75th percentiles with a line indicating the median, whiskers extend 1.5 times past the length of the box, and dots represent data points beyond the whiskers. 

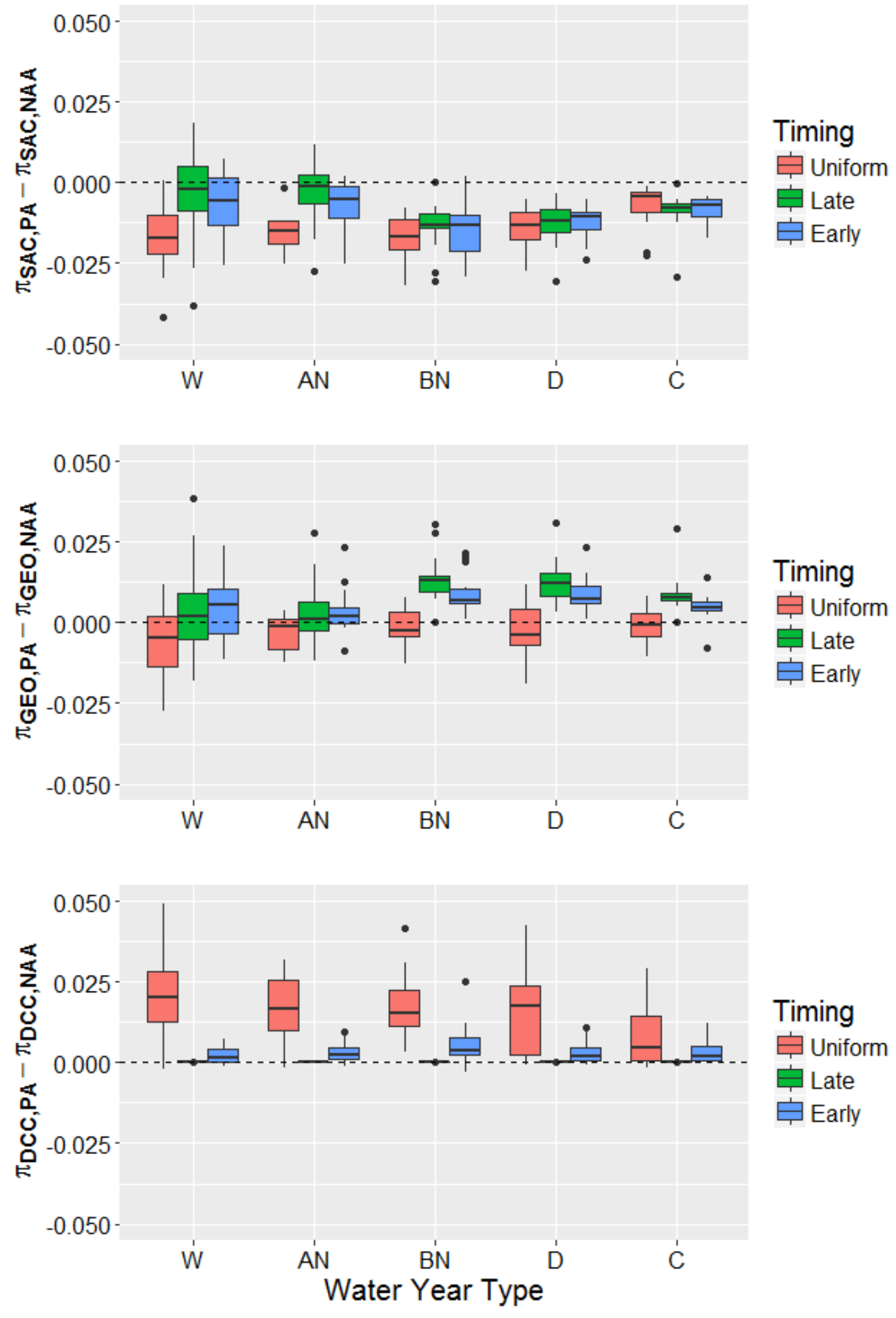

Figure 26. Boxplots showing difference in predicted mean annual probability $(\pi)$ of juvenile Chinook salmon entrainment between No Action Alternative (NAA) and Proposed Action (PA) for each route (SAC = Sacramento River, $\mathrm{GEO}=$ Georgiana Slough, $\mathrm{DCC}=$ Delta Cross Channel) by water year type (W=Wet, AN=Above Normal, $\mathrm{BN}=$ Below Normal, $\mathrm{D}=\mathrm{Dry}, \mathrm{C}=$ Critical) and run-timing scenario, Sacramento-San Joaquin River Delta, northern California. Boxes range from the 25th to the 75th percentiles with a line indicating the median, whiskers extend 1.5 times past the length of the box, and dots represent data points beyond the whiskers. 
The difference in entrainment between scenarios primarily was controlled by the difference in operation of the DCC between PA and NAA. Under the PA scenario, the DCC was open more frequently, thus exposing more fish to being entrained into the interior Delta through the DCC. Two triggers were assumed in the modeling to require the DCC to close: (1) Flow below the NDD exceeding 25,000 $\mathrm{ft}^{3} / \mathrm{s}$ (because of flood/scour concerns at the DCC), and (2) flow at Wilkins Slough on the Sacramento River exceeding $7,500 \mathrm{ft}^{3} / \mathrm{s}$ (based on a hydrological criterion included in actual DCC gate operation management to warn of salmon presence in the system). Water diversions have no effect on flow at Wilkins Slough, which leaves the flow downstream of the diversion as the primary driver of the differences between entrainment under the PA and NAA scenarios. Diversions under the PA reduced the flow to less than $25,000 \mathrm{ft}^{3} / \mathrm{s}$, thus increasing the number of days the DCC could remain open. This was particularly evident in October and November during wet and above normal water year types when discharge upstream of the diversion was $>25,000 \mathrm{ft}^{3} / \mathrm{s}$. For example, under PA in October during wet years, the DCC was open for about 3 more days than under the NAA scenario. During drier water year types, the DCC was operated similarly for PA and NAA because flows in those years rarely exceeded $25,000 \mathrm{ft}^{3} / \mathrm{s}$. When the DCC was operated in a similar manner between scenarios (drier years), entrainment to the interior was higher under both scenarios owing to the general relationship between flow and entrainment to the interior Delta. Under lower flows, entrainment to the interior Delta is higher because of tidal forcing at the Georgiana Slough divergence (Perry, 2010; Perry and others, 2015).

Perry and others (2013) examined the sensitivity of overall survival of emigrating juvenile Chinook salmon to changes in entrainment into the interior Delta. In this analysis, they determined that completely eliminating entrainment to the interior Delta resulted in a 2-7 percentage point increase in overall survival through Delta, under the assumption of no change in route-specific survival. Thus, we expect that a 3-5 percentage point difference in the probability of being entrained to the interior Delta between PA and NAA would contribute relatively little to the change in overall survival. However, reduced inflows to the Delta owing to the NDD may simultaneously influence both route-specific survival and migration routing. Such simultaneous changes may result in larger expected changes in survival than the effect of routing alone on overall survival. 


\section{References Cited}

Bradford, M.J., and Higgins, P.S., 2001, Habitat-, season-, and size-specific variation in diel activity patterns of juvenile Chinook salmon (Oncorhynchus tshawytscha) and steelhead trout

(Oncorhynchus mykiss): Canadian Journal of Fisheries and Aquatic Sciences, v. 58, no. 2, p. 365374.

Chapman, E.D., Hearn, A.R., Michel, C.J., Ammann, A.J., Lindley, S.T., Thomas, M.J., Sandstrom, P.T., Singer, G.P., Peterson, M.L., MacFarlane, R.B., and Klimley, A.P., 2013, Diel movements of out-migrating Chinook salmon (Oncorhynchus tshawytscha) and steelhead trout (Oncorhynchus mykiss) smolts in the Sacramento/San Joaquin watershed: Environmental Biology of Fishes, v. 96, nos. 2-3, p. 273-286.

California Department of Water Resources, 2013, Bay Delta conservation plan-Public draft: Prepared by ICF International for California Department of Water Resources, Sacramento, California, 1396 p. del Rosario, R.B., Redler, Y.J., Newman, K., Brandes, P.L., Sommer, T., Reece, K., and Vincik, R., 2013, Migration patterns of juvenile winter-run-sized Chinook salmon (Oncorhynchus tshawytscha) through the Sacramento-San Joaquin Delta: San Francisco Estuary and Watershed Science, v. 11, p. $1-22$.

Faraway, J.J., 2006, Extending the linear model with R: Boca Raton, Florida, Chapman and Hall. Hosmer, D.W., and Lemeshow, S., 2000, Applied logistic regression: Hoboken, New Jersey, Wiley, $392 \mathrm{p}$.

ICF International, 2016, Biological assessment for the California WaterFix: Prepared for the Bureau of Reclamation, Sacramento, California, ICF 00237.15., 62 p.

Kapahi, G., Baer, I., Farwell, J., Riddle, D., and Wilson, G., 2006, Water quality control plan for the San Francisco Bay/Sacramento-San Joaquin Delta Estuary: Sacramento, California, State Water Resources Control Board, 49 p.

Perry, R.W., 2010, Survival and migration dynamics of juvenile Chinook salmon (Oncorhynchus tshawytscha) in the Sacramento-San Joaquin River Delta: University of Washington, Seattle, School of Aquatic and Fishery Sciences, Ph.D. dissertation, 223 p.

Perry, R.W., Skalski, J.R., Brandes, P.L., Sandstrom, P.T., Klimley, A.P., Ammann, A., and MacFarlane, B., 2010, Estimating survival and migration route probabilities of juvenile Chinook salmon in the Sacramento-San Joaquin River Delta: North American Journal of Fisheries Management, v. 30, p. 142-156.

Perry, R.W., Brandes, P.L., Burau, J.R., Klimley, A.P., MacFarlane, B., Michel, C., and Skalski, J.R., 2013, Sensitivity of survival to migration routes used by juvenile Chinook salmon to negotiate the Sacramento-San Joaquin River Delta: Environmental Biology of Fishes, v. 96, p. 381-392.

Perry, R.W., Brandes, P.L., Burau, J.R., Sandstrom, P.T., and Skalski, J.R., 2015, Effect of tides, river flow, and gate operations on entrainment of juvenile salmon into the interior Sacramento-San Joaquin River Delta: Transactions of the American Fisheries Society, v. 144, p. 445-455.

Perry, R.W., Romine, J.G., Adams, N.S., Blake, A.R., Burau, J.R., Johnston, S.V., and Liedtke, T.L. 2014. Using a non-physical behavioral barrier to alter migration routing of juvenile Chinook salmon in the Sacramento-San Joaquin River Delta. River Research and Applications. v. 30, p, 192-203. 


\section{Appendix 1. Sensitivity Analysis-Differences between Scenarios for Day and Night Entrainment}
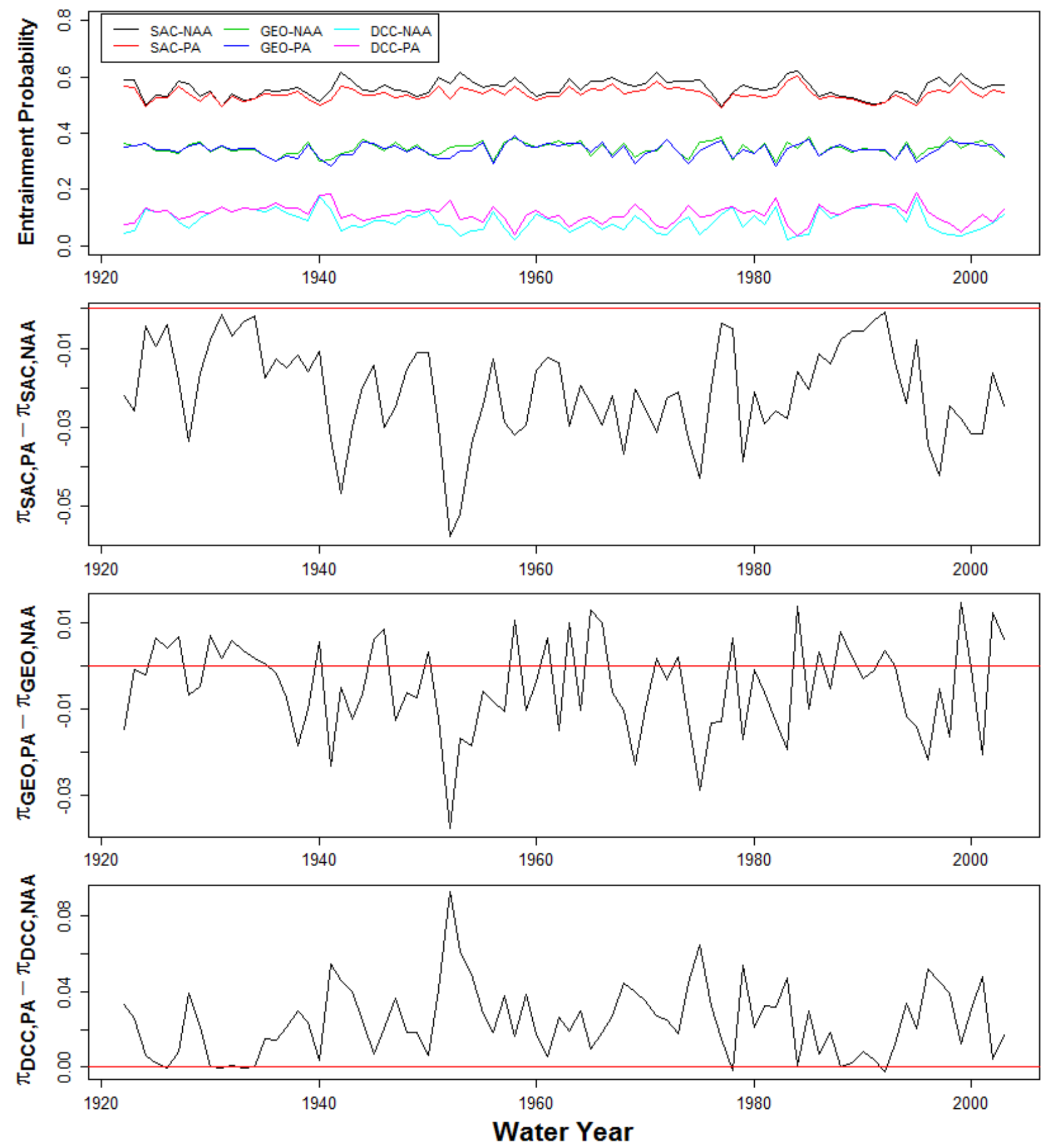

Figure 1.1. Graphs showing comparison of predicted mean annual probability $(\pi)$ of juvenile Chinook salmon entrainment during daytime hours assuming uniform run timing for the Sacramento River (SAC), Georgiana Slough (GEO), and Delta Cross Channel (DCC) between the Proposed Action (PA) and No Action Alternative (NAA), Sacramento-San Joaquin River Delta, northern California, water years 1922-2003. Mean annual entrainment probabilities (top graph) and the difference in entrainment between scenarios for SAC, GEO, and DCC (bottom three graphs, respectively) are shown. Values above horizontal red line indicate greater entrainment under the PA scenario. 

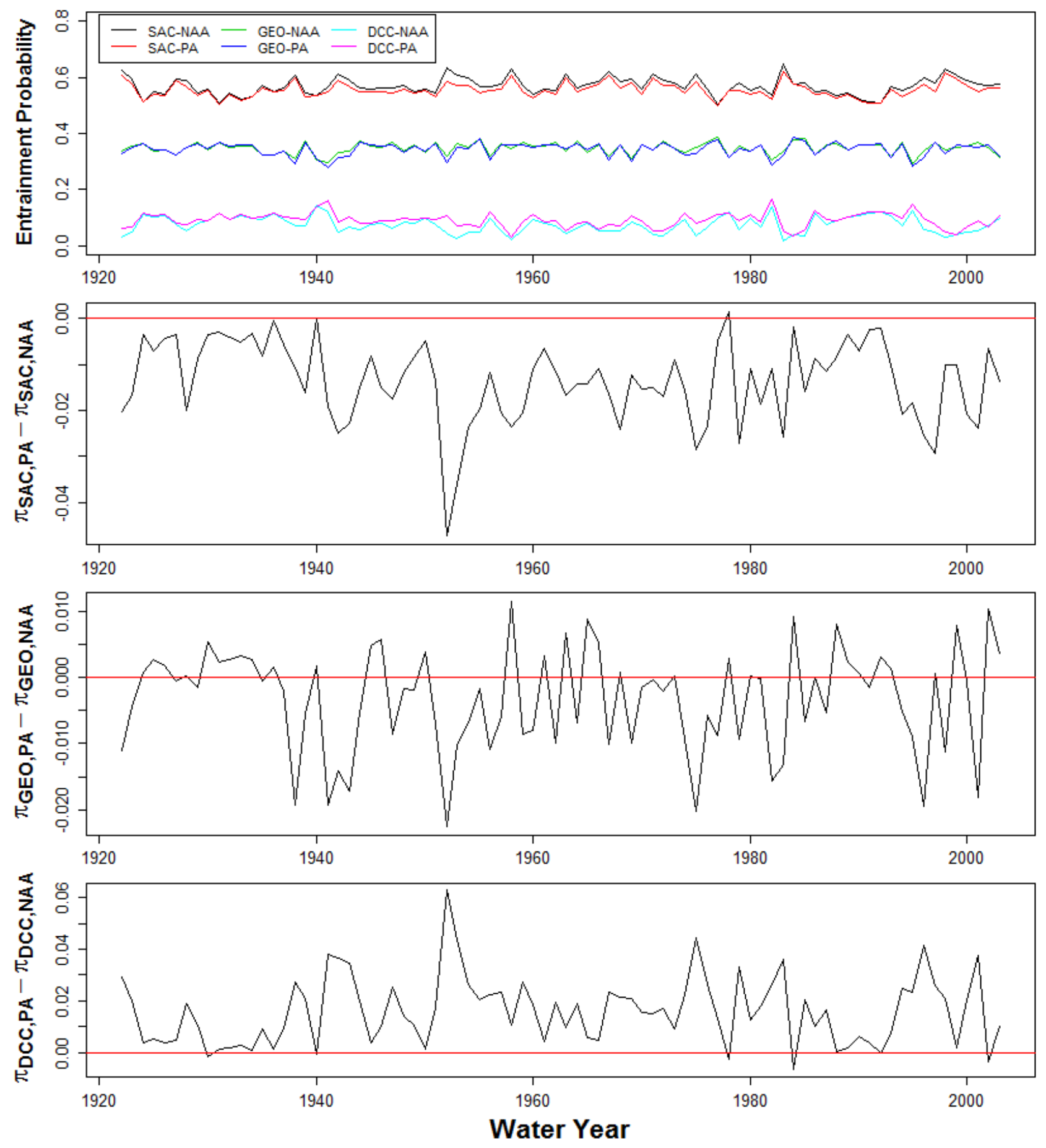

Figure 1.2. Graphs showing comparison of predicted mean annual probability $(\pi)$ of juvenile Chinook salmon entrainment during nighttime hours assuming uniform run timing for the Sacramento River (SAC), Georgiana Slough (GEO), and Delta Cross Channel (DCC) between the Proposed Action (PA) and No Action Alternative (NAA), Sacramento-San Joaquin River Delta, northern California, water years 1922-2003 Mean annual entrainment probabilities (top graph) and the difference in entrainment between scenarios for SAC, GEO, and DCC (lower panels). Values above the horizontal red line indicate greater entrainment under the PA scenario. 
Publishing support provided by the U.S. Geological Survey

Science Publishing Network, Tacoma Publishing Service Center

For more information concerning the research in this report, contact the Director, Western Fisheries Research Center

U.S. Geological Survey

6505 NE 65th Street

Seattle, Washington 98115

https://wfrc.usgs.gov/ 


\section{$\frac{1}{3}$}

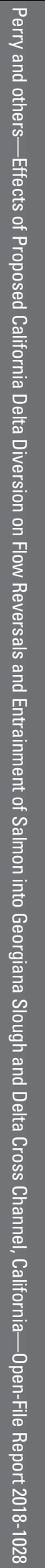

ISSN 2331-1258 (online) 